\title{
Tsunami-induced coastal change: scenario studies for Painan, West Sumatra, Indonesia
}

\author{
Linlin $\mathrm{Li}^{1}$, Zhenhua Huang ${ }^{1,2}$, Qiang Qiu ${ }^{1}$, Danny H. Natawidjaja ${ }^{3}$, and Kerry Sieh ${ }^{1}$ \\ ${ }^{1}$ Earth Observatory of Singapore, Nanyang Technological University, Singapore \\ ${ }^{2}$ School of Civil and Environmental Engineering, Nanyang Technological University, Singapore \\ ${ }^{3}$ Research Center for Geotechnology, Indonesian Institute of Sciences (LIPI), Bandung, Indonesia
}

(Received October 31, 2010; Revised May 29, 2011; Accepted August 2, 2011; Online published October 24, 2012)

\begin{abstract}
There exists a high probability of a great earthquake rupture along the subduction megathrust under the Mentawai Islands of West Sumatra in the near future. Six rupture models were used to assess the tsunami inundation and the accompanying sediment movement in Painan, West Sumatra, Indonesia. According to a worst scenario, the potential tsunami might hit the coast of Painan about 26 minutes after the rupture and the entire city could be inundated with a maximum inundation depth of about $7 \mathrm{~m}$. Severe erosion may also occur in the near-shore region. Two scenarios, one scenario with a positive leading wave and the other with a negative leading wave, were selected to simulate the tsunami-induced morphological changes. A positive leading wave would cause severe erosion in the shoreline area and a large sandbar in the offshore area adjacent to the shoreline; a small amount of sediment could be deposited in the city area; a negative leading wave could cause moderate erosion in the further offshore area due to the strong retreating wave front, an offshore sandbar could form in the bay area, while no noticeable large area of sand deposit could be found in the city area. The difference in the erosion and deposition patterns between these two scenarios provides very helpful information in the investigation of historical tsunamis through tsunami deposits.
\end{abstract}

Key words: Coastal erosion, tsunami inundation, shoreline changes, sediment transport, West Sumatra megathrust.

\section{Introduction}

The Sunda megathrust is located at a convergent plate boundary where it forms the interface between the overriding Eurasian plate and the subducting Indo-Australian plate. Several large sections of the megathrust have ruptured sequentially in the past decade, causing a series of earthquakes along the western coast of Sumatra: the largest of these failures is the giant Aceh-Andaman earthquake of $M_{\mathrm{w}} 9.15$ in 2004 caused by a $1600-\mathrm{km}$ long rupture along the magathrust (Sieh, 2007); the great Nias earthquake of March 28, 2005 ruptured another segment south to the Aceh earthquake segment. These rapid failures have raised great concern about the unbroken Mentawai segment(Aydan, 2008; McCloskey et al., 2005; Nalbant et al., 2005; Natawidjaja et al., 2006; Natawidjaja and Triyoso, 2007; Sieh, 2007). According to the studies of McCloskey et al. (2005) and Nalbant et al. (2005), the rupture of adjoining 1600- and 300-km sections of the Sunda megathrust in December 2004 and March 2005 has increased the stresses on the megathrust immediately to the south, under the Batu and Mentawai islands. The increased stresses have significantly boosted the possibility of earthquake and tsunami hazard in West Sumatra. Historically, two great earthquakes of 1797 and 1833 have happened in this 700-

Copyright (C) The Society of Geomagnetism and Earth, Planetary and Space Sciences (SGEPSS); The Seismological Society of Japan; The Volcanological Society of Japan; The Geodetic Society of Japan; The Japanese Society for Planetary Sciences; TERRAPUB.

doi:10.5047/eps.2011.08.002 kilometer-long unbroken Mentawai segment (Natawidjaja et al., 2006). Geodetic and paleogeodetic measurements have revealed that the slip deficit accumulated in this area has already exceeded the slip occurred during the 1797 earthquake and is slowly reaching the slip occurred during the 1833 earthquake (Chlieh et al., 2008). This information indicates that the unbroken Mentawai segment may already be advanced in the seismic supercycle, which has a period about 200 years according to palaeoseismologic studies (Zachariasen et al., 1999; McCloskey et al., 2005; Sieh et $a l ., 2008)$. The imminent hazard in this area is vindicated by the megathrust rupture of September 2007. However, only a small amount of the accumulated potential slip has been relieved by the 2007 earthquake and its aftershocks (Aydan, 2008; Konca et al., 2008); larger earthquakes approaching the size of 2004 Aceh-Andaman earthquake might be possible in the near future (Sieh et al., 2008; Natawidjaja et al., 2009).

As the Mentawai section of the Sunda megathrust is very close to the coast of West Sumatra, potential ruptures and subsequently triggered tsunamis may pose a significant threat to the people and property in the nearby cities. Several rupture models for the unbroken Mentawai segment have been proposed (Tobita, 2007; Aydan, 2008; Chlieh et al., 2008; Natawidjaja et al., 2009) and used by some researchers (Borrero et al., 2006; McCloskey et al., 2008; Taubenbock et al., 2009; Muhari et al., 2010) in an attempt to assess the tsunami threat to the major cities along the 


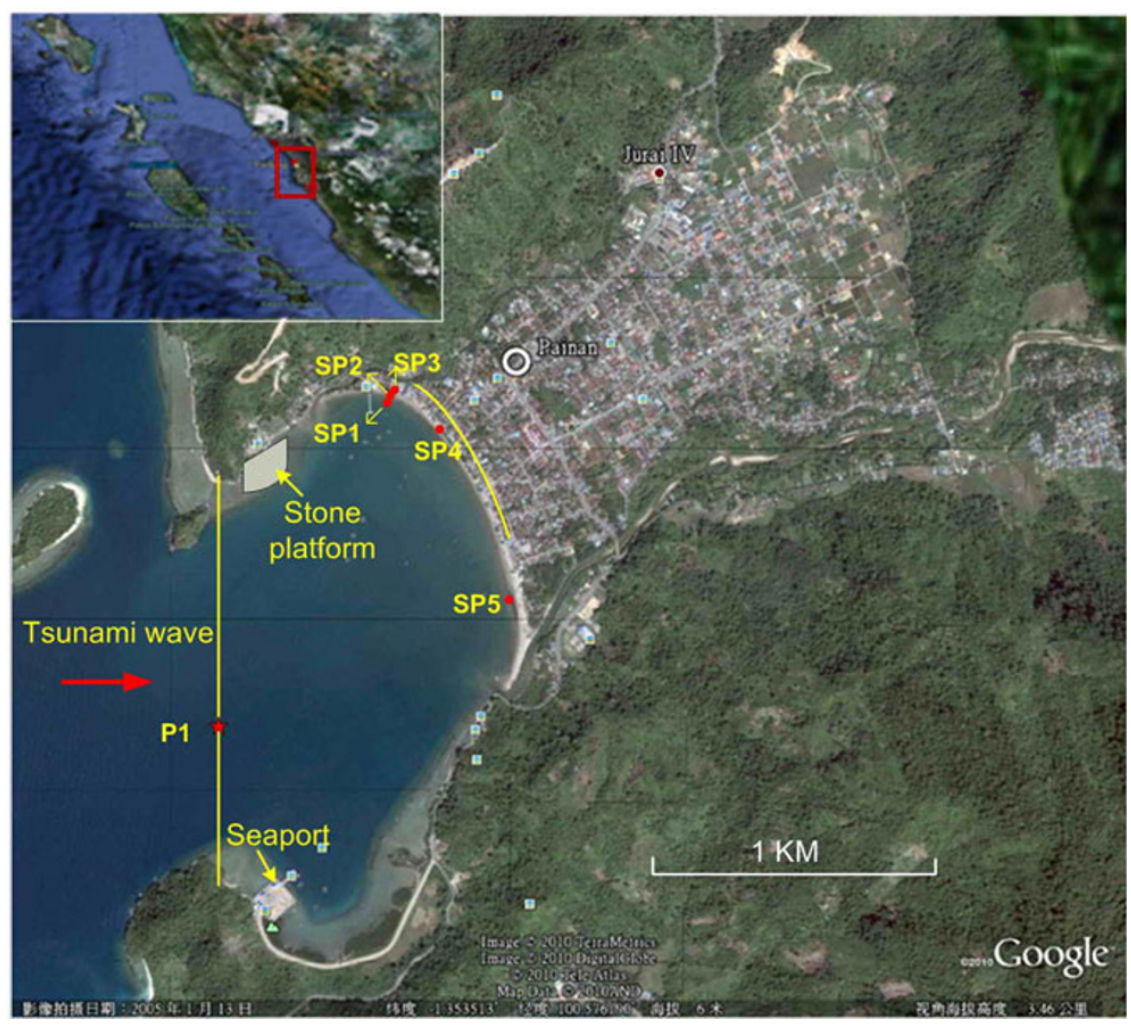

Fig. 1. A Google image of Painan. Red dots are the locations of sand samples taken. The yellow line in the city area indicates the cement road next to the shoreline with an average distance of $60 \mathrm{~m}$ from the shoreline.

coast of western Sumatra, including Padang, Bengkulu and Painan. Tsunami arrival time, tsunami height and inundation map were presented for these proposed scenarios. The results of these studies indicate that the maximum tsunami height along the coast of Padang and Painan could reach 5$10 \mathrm{~m}$ (Borrero et al., 2006; McCloskey et al., 2008; Muhari et al., 2010). We noticed that the tsunami-induced sediment transport was not considered in all these studies. However, tsunami waves with the height of 5-10 m will be inevitably accompanied by very high flow velocities when they penetrate inland (Imamura et al., 2001; Matsutomi et al., 2006; Goto et al., 2007), which will undoubtedly produce high bed shear stresses and sediment movements over large areas, resulting in beach erosion, scouring around coastal structures, and widespread deposition in inland areas (Gelfenbaum and Jaffe, 2003; Srinivasalu et al., 2007; Pari et al., 2008; Meilianda et al., 2010; Paris et al., 2010). Relative to other tsunami behaviors, sediment transport is one of the poorest understood characteristics as it is almost impossible to conduct detailed real-time measurements during tsunami events.

Understanding tsunami-induced sediment movement is also extremely important for tsunami geologists who have made significant effort to estimate the tsunami heights, flow depths and velocities by establishing qualitative relationships between tsunami deposits and tsunami hydrodynamic characteristics (Jaffe and Gelfenbuam, 2007; Moore et al., 2007; Morton et al., 2008; Spiske et al., 2010). The information derived by inverse modeling from paleo-tsunami deposits, can further help us understand tsunami sources and attendant tectonic character of a particular region in some detail (Bourgeois, 2009; Martin et al., 2008; Nelson et al., 2006). However, the inverse modeling faces great challenges since sediment movement is highly depended on tsunami wave form, bathymetry and topography near shoreline and sediment sources. Forward numerical modeling of tsunami-induced sediment transport could provide quantitative information in terms of tsunami height, flow velocity, and tsunami deposit characteristics to help understand the complex patterns of erosion and sedimentation process in both onshore and seaward directions (Goto and Imamura, 2007).

In this study, we perform a scenario-based study for the city of Painan, with a focus on the sediment movement and morphological changes in the coastal area of Painan, using potential rupture models proposed for the unbroken Mentawai section. Painan is chosen in this study because it lies between two hills (as shown in Fig. 1), which potentially can cause flow channelling effect and increase the inundation distance. The main objectives of this study are to assess the tsunami inundation threats to Painan and to understand the changes of beach profile and the characteristics of sediment deposit for representative fault rupture models. The effects of a shore-parallel road on the beach profile changes will be discussed as well. The information on the inundation will be useful for the local authorities to design evacuation routes and the information on the sediment erosion and deposition will be useful for tsunami geologists to study paleo-tsunamis in this area. Brief descriptions of the hydrodynamic model and the sediment transport model are given in Section 2. Details of the data preparation for our simulations are described in Section 3. Simulation re- 
sults of inundation and sediment transport are discussed in Section 4. Main findings are summarized in Section 5.

\section{Numerical Models}

The software package COMCOT (Cornell Multi-grid Coupled Tsunami Model) is used to simulate the tsunami generation, propagation and inundation. Description and applications of COMCOT can be found in Liu et al. (1995), Wang and Liu (2005) and Wijettunge et al. (2008), Huang et al. (2009) and Megawati et al. (2009). The software package XBeach, which is a $2 \mathrm{DH}$ numerical model for simulating the nearshore response to hurricanes and storms, is used to simulate the sediment transport. The model can seamlessly simulate wave propagation, inundation, sediment transport and morphological changes (including dune erosion, overwash and breaching) under various wave and flow conditions. A detailed description of XBeach can be found in Roelvink et al. (2009). The model has been tested with not only several analytical solutions, large-scale laboratory experiments, but also several field observations (Roelvink et al., 2009; Deltares, 2010):

i) The ability of the model to predict the runup and rundown processes of non-breaking long waves has been tested against 1D (Carrier and Greenspan, 1958) and 2D (Ozkan-Haller and Kirby, 1997) analytical solutions.

ii) The model has also been tested by a series of largescale experiments in which real beach profiles and real storm conditions were scaled and reproduced in a $233 \mathrm{~m}$ long, $7 \mathrm{~m}$ deep and $5 \mathrm{~m}$ wide wave flume (Deltares, 2010). The sand beaches were exposed to various wave conditions, and the dune erosion and retreat process were measured in the experiments and also simulated using XBeach. It was concluded that the calculated wave heights, flow velocities, sediment concentrations as well as sediment transports rates compared reasonable well with the measurements.

iii) XBeach has also been used to simulate the morphodynamic responses of sandy dunes to an extreme storm at Assateague Island, Maryland, USA (Jimenez et al., 2006). The calculated changes of bed profile were found to be largely consistent with the measured data. The model has been applied to several case studies involving dune erosion and sediment deposition during Hurricanes Ivan and Katrina (Lindemer et al., 2010; McCall et al., 2010). Their numerical results demonstrate reasonable erosion and deposition patterns, indicating that the model is capable of handling practical situations with large wave heights (larger than $5 \mathrm{~m}$ ) and long durations (20 hrs or more).

Wind waves are not considered in this study, thus shallow water equations are adopted to calculate the flow field without wave radiation stresses. The performance of the model without considering wind waves has been validated against several laboratory experiments on the transports of fine sand on uniform slopes under breaking solitary waves (Kobayashi and Lawrence, 2004; Young et al., 2010). Since $\mathrm{XBeach}$ is a $2 \mathrm{DH}$ model, the sediment entrainment by turbulent flows and the density stratification in sediment-laden flows (both are related to the vertical flow structure) cannot be simulated.

\subsection{Nonlinear shallow water equations}

Both COMCOT and XBeach solve the following depthaveraged nonlinear shallow water equations to obtain the near-shore velocity field,

$$
\begin{aligned}
& \frac{\partial \eta}{\partial t}+\frac{\partial h u}{\partial x}+\frac{\partial h v}{\partial y}=0 \\
& \frac{\partial u}{\partial t}+u \frac{\partial u}{\partial x}+v \frac{\partial u}{\partial y}+\frac{c_{f} u \sqrt{u^{2}+v^{2}}}{h}=-g \frac{\partial \eta}{\partial x} \\
& \frac{\partial v}{\partial t}+u \frac{\partial v}{\partial x}+v \frac{\partial v}{\partial y}+\frac{c_{f} v \sqrt{u^{2}+v^{2}}}{h}=-g \frac{\partial \eta}{\partial y}
\end{aligned}
$$

where $\eta$ is the surface elevation; $h$ is the total water depth; $u, v$ are the depth-averaged velocities in $x$ - and $y$-directions, respectively; $g$ is the gravitational acceleration; $c_{f}$ is an empirical bed friction coefficient. Normally, a larger friction coefficient should be chosen for city areas where the presence of city buildings will increase the resistance to tsunami flows; according to previous studies (Qiu et al., 2010; Huang et al., 2011), the increased flow resistance in a coastal city may slightly raise the flow depth near the shoreline and reduce the inundation depth in the city area, which could also slightly affect the flow field and sediment transport. In our simulations, the flow resistance from the city buildings is not taken into account and $c_{f}=0.003$ is simply used (the default value in XBeach). Thus the inundation depths presented in this paper are considered as the worst case scenarios.

When running COMCOT to simulate the tsunami wave propagation in deep oceans, the shallow water equations are solved in a spherical coordinate system and the effects of Coriolis force are added to Eqs. (2) and (3). See Liu et al. (1995), Wang and Liu (2005) or Wijettunge et al. (2008) for details. The coupling of COMCOT and XBeach for simulating tsunami-induced sediment transport and beach profile changes is described at the end of Subsection 3.2.

\subsection{Sediment transport model}

The sediment transport is modeled by a depth-averaged advection diffusion equation with a source term based on the concept of equilibrium sediment concentration (Galappatti and Vreugdenhil, 1985):

$$
\frac{\partial h C}{\partial t}+\frac{\partial h C u}{\partial x}+\frac{\partial h C v}{\partial y}=\frac{h C_{\mathrm{eq}}-h C}{T_{s}}
$$

where $C$ is the depth-averaged concentration of suspended sediment. The sediment diffusion is represented by an adaptation time $T_{s}$, which is a function of the local water depth and the sediment fall velocity $w_{s} . C_{\text {eq }}$ is the equilibrium sediment concentration calculated using a chosen sediment transport formula. The formula proposed by van Rijn (1993) is used to calculate the equilibrium sediment concentration; The expressions for $C_{\mathrm{eq}}$ and $T_{s}$ are given in Appendix. Since XBeach is a numerical 2DH model, the effects of density stratification and hindered settling (Apotsos et al., 2011) can only be considered indirectly through the adaptation time $T_{s}$ and the equilibrium sediment concentration $C_{\text {eq }}$. 
Table 1. Fault parameters of earthquake scenarios used in tsunami simulations.

\begin{tabular}{|c|c|c|c|c|c|c|c|c|c|}
\hline Scenario & $M_{\mathrm{W}}$ & $\begin{array}{c}\text { No. of } \\
\text { segment }\end{array}$ & $\begin{array}{c}\text { Length } \\
(\mathrm{km})\end{array}$ & $\begin{array}{l}\text { Width } \\
(\mathrm{km})\end{array}$ & $\begin{array}{l}\text { Epi. } \\
\text { Lon. }\end{array}$ & $\begin{array}{l}\text { Epi. } \\
\text { Lat. }\end{array}$ & $\begin{array}{l}\text { Slip } \\
(\mathrm{m})\end{array}$ & $\begin{array}{c}\text { Depth } \\
(\mathrm{km})\end{array}$ & $\begin{array}{c}\text { Dip } \\
\text { (degree) }\end{array}$ \\
\hline \multirow{4}{*}{$\mathrm{SA}^{*}$} & \multirow{4}{*}{8.7} & 1 & 220 & 135 & 98.2 & -1.8 & 6 & $5-40$ & 15 \\
\hline & & 2 & 70 & 112 & 99.0 & -2.8 & 8 & $5-34$ & 15 \\
\hline & & 3 & 66 & 128 & 99.3 & -3.3 & 6 & $5-38$ & 15 \\
\hline & & 4 & 16 & 155 & 99.6 & -3.6 & 4 & $5-45$ & 15 \\
\hline \multirow{3}{*}{$\mathrm{SB}^{* *}$} & \multirow{3}{*}{8.9} & 1 & 30 & 174 & 99.0 & -2.9 & 9 & $5-50$ & 15 \\
\hline & & 2 & 70 & 174 & 99.3 & -3.3 & 11 & $5-50$ & 15 \\
\hline & & 3 & 180 & 124 & 100.0 & -4.2 & 18 & $5-37$ & 15 \\
\hline $\mathrm{S} 1$ & 8.8 & 348 & 20 & 20 & I & I & 1 & I & 13 \\
\hline $\mathrm{S} 2$ & 8.92 & 348 & 20 & 20 & 1 & I & 1 & I & 13 \\
\hline S3 & 8.7 & 1 & 370 & 95 & 98.8 & -1.22 & 10 & 10 & 13 \\
\hline S4 & 8.8 & 1 & 450 & 117 & 99.01 & -1.52 & 6 & 10 & 13 \\
\hline
\end{tabular}

The change of bottom elevation is updated by the following continuity equation:

$$
\frac{\partial z_{b}}{\partial t}+\frac{1}{1-p}\left(\frac{\partial q_{x}}{\partial x}+\frac{\partial q_{y}}{\partial y}\right)=0
$$

where $p$ is the porosity of bed material. $q_{x}$ and $q_{y}$ are given by:

$$
\begin{aligned}
& q_{x}=\frac{\partial h C u}{\partial x} \\
& q_{y}=\frac{\partial h C v}{\partial y}
\end{aligned}
$$

which represent the sediment transport rates in $x$ - and $y$ directions, respectively.

Multiple sand layers, which are composed of multiple sediment classes, can be considered by assigning different grain sizes in different areas. These features make it possible for tracking sediment movement and discussing characteristics of tsunami deposits such as landward fining.

\section{Model Setup}

\subsection{Tsunami sources}

Key fault parameters of the six tsunami sources used in this study are listed in Table 1. The key parameters of two historical great earthquakes (1797 earthquake and 1833 earthquake, which are SA and SB in Table 1, respectively) were inferred from coral microatolls by Natawidjaja et al. (2006), which were also used by Borrero et al. (2006) to investigate the tsunami inundation map in Padang and Bengkulu. Based on the geodetic and paleogeodetic measurements of interseismic strain above the Mentawai section of the Sunda subduction zone, moment deficit in Mentawai megathrust was inferred (Natawidjaja et al., 2006; Chlieh et al., 2008), and two plausible rupture scenarios with $8.8 M_{\mathrm{w}}$ and $8.92 M_{\mathrm{w}}$ were proposed (Natawidjaja et al., 2009). These two scenarios ( $S 1$ and S2 in Table 1) have sophisticated inhomogeneous slip distribution information, and were used by German-Indonesia Tsunami Early Warning(GI-TEWS) and the Ministry of Marine Affairs and Fisheries, Indonesia for the inundation modelling and hazard mapping for Padang (Goseberg and Schlurmann, 2008; Muhari et al., 2010). In these two fault rupture models, the currently locked zone at Mentawai patch was divided into 348 fault subsets with each segment having a size of $20 \mathrm{~km} \times 20 \mathrm{~km}$ (Chlieh et al., 2008). Based on the strain and stress rates of Sumatra Fault calculated from the GPS measurements in Indonesia and its close vicinity, Aydan (2008) predicted an earthquake of magnitude 8.7 in the offshore area of Siberut and Sipora islands, with a rupture length of 400-450 km and an epicentre about $260 \mathrm{~km}$ away from the west coast of Sumatra. Tobita (2007) also predicted a $M_{\mathrm{w}} 8.4-8.8$ earthquake with a rupture length of $370 \mathrm{~km}$ in the study area according to Synthetic Aperture Radar (SAR) interferometry data in West Sumatra. Since no detailed parameters of these two scenarios were given in the original papers except the potential magnitudes and fault lengths, we adopted the fault parameters in Muhari et al. (2010) except that the slips had been changed to satisfy the specified magnitudes, and listed these two models as S3 and S4 in Table 1.

In this study, the seafloor displacement is calculated by using the rupture model of Okada (1985). Since earthquake rupture velocities are large with respect to tsunami phase speeds, we have assumed that the initial surface elevation will simply follow the sea floor deformation instantaneously. The initial sea surface elevations for all source models are given in Fig. 2.

\subsection{Offshore boundary condition}

The open boundary conditions in XBeach have been modified to take as inputs the time series of sea surface elevation and incident wave velocity, which can be obtained from other large-scale numerical simulations or field survey data. For this study, the offshore boundary conditions used for sediment transport simulations are provided by running the hydrodynamic model COMCOT (Cornell Multigrid Coupled Tsunami model) (Liu et al., 1995; Wang and Liu, 2005; Wijettunge et al. 2008). Nested grids were used in COMCOT to improve the computational efficiency and numerical accuracy (see Fig. 3). The information on the nested grids is summarized in Table 2. On all open boundaries, radiation boundary conditions are used to minimize the possible wave reflection from the numerical boundaries. When waves are moving on a beach, a wet-dry algorithm is used to track the moving water line.

$\mathrm{XBeach}$ is used to simulate the sediment transport in the 

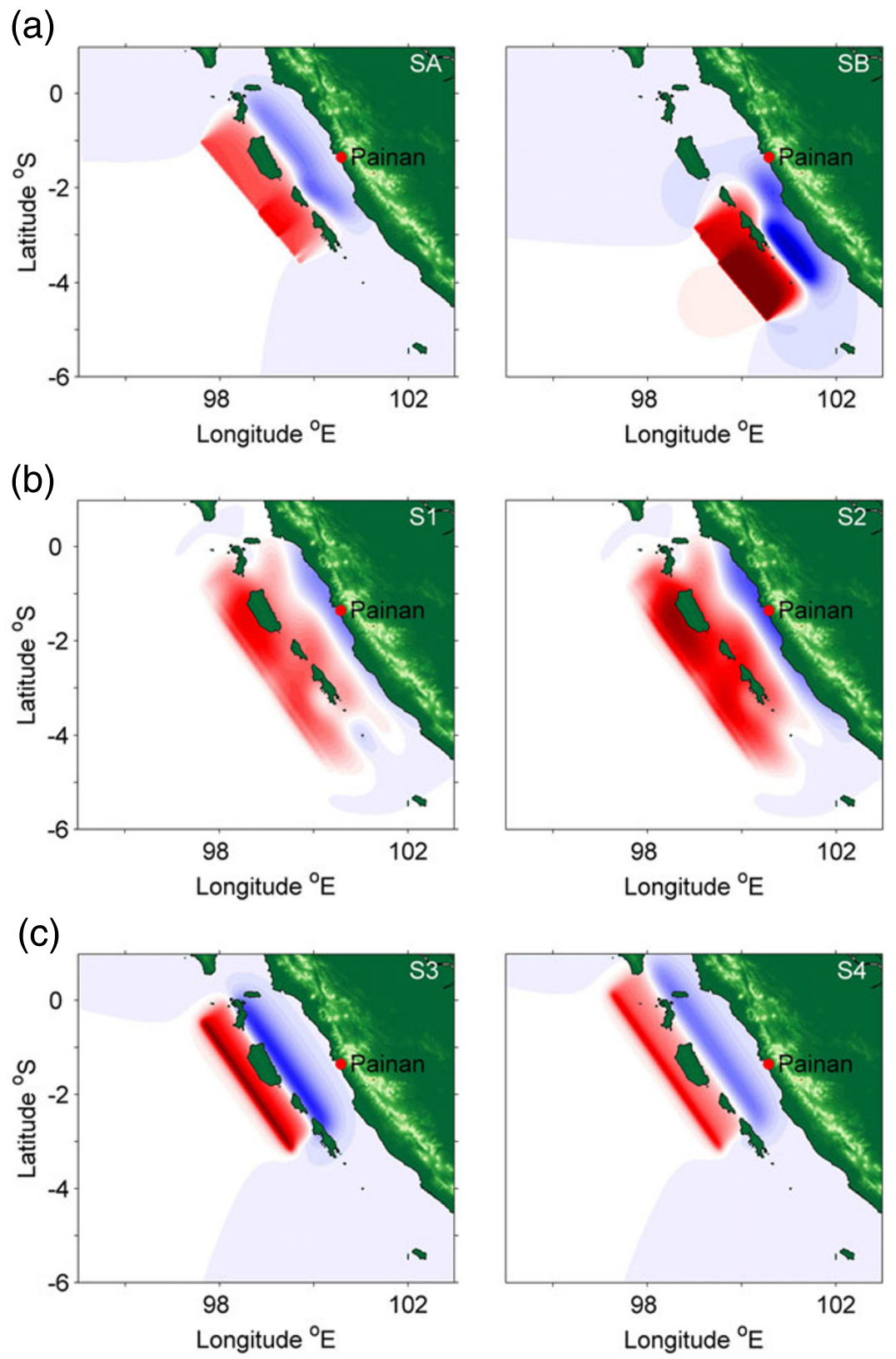

(m)

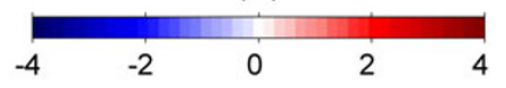

Fig. 2. Initial surface elevation map of the six scenarios.

Painan Bay and the city area which are covered by the innermost grid (grid $\mathrm{C}$ in Fig. 3). To run XBeach, the incoming wave conditions must be specified on the offshore boundary; to achieve that, we first run COMCOT for each fault rupture model to get the time series of the surface elevation and velocity on this boundary, then interpolate the surface elevation and velocity from COMCOT simulation using the time step and spatial spacing required by XBeach simulations.

Figure 4 shows sample time series of the incident tsunami waves at P1 (shown in Fig. 1) for the six scenarios listed in Table 1. For the scenarios SA, SB, S3 and S4, the leading waves are negative waves; while for the scenarios S1 and
S2, the leading waves are positive waves, with maximum wave heights of nearly $5 \mathrm{~m}$ and $7 \mathrm{~m}$, respectively.

To estimate the significance of possible wave reflection from the Painan beach, we re-run COMCOT with artificial damping layers introduced in the bay area and the city area (Manning coefficient is gradually increased from the bay area to the city area), and then compared the surface elevations with those in Fig. 4; no significant difference was found. We conclude that it is not necessary to pay special attention to the wave reflection from the Painan beach in the numerical simulations.

For all sediment transport simulations, the time series of surface elevation and water velocity at the offshore bound- 
Table 2. Information on the setup of the four grids for COMCOT.

\begin{tabular}{|c|c|c|c|c|}
\hline & Grid 0 & Grid A & Grid B & Grid C (Painan) \\
\hline Number of grids & $481 \times 421$ & $723 \times 723$ & $543 \times 543$ & $680 \times 680$ \\
Latitude scope (degree) & $95 \mathrm{E}$ to $103 \mathrm{E}$ & $98 \mathrm{E}$ to $102 \mathrm{E}$ & $100 \mathrm{E}$ to $101 \mathrm{E}$ & $100.4 \mathrm{E}$ to $100.65 \mathrm{E}$ \\
Longitude scope (degree) & $6 \mathrm{~S}$ to $1 \mathrm{~N}$ & $4 \mathrm{~S}$ to $0 \mathrm{~N}$ & $1.8 \mathrm{~S}$ to $0.8 \mathrm{~S}$ & $1.45 \mathrm{~S}$ to $1.2 \mathrm{~S}$ \\
Grid size (m) & 1850 & 616.67 & 205.56 & 41.07 \\
Parent grid & None & Grid 0 & Grid A & 5 \\
Ratio to parent grid & None & 3 & 3 & 0.15 \\
Time step (sec) & 1.2 & 0.6 & 0.3 & Cartesian \\
Coord. system & Spherical & Spherical & Spherical & Nonlinear \\
SWE type & Linear & Linear & Linear & Non-zero \\
Manning roughness & 0 & 0 & 0 & \\
\hline
\end{tabular}

$\mathrm{SWE}=$ Shallow Water Equations.

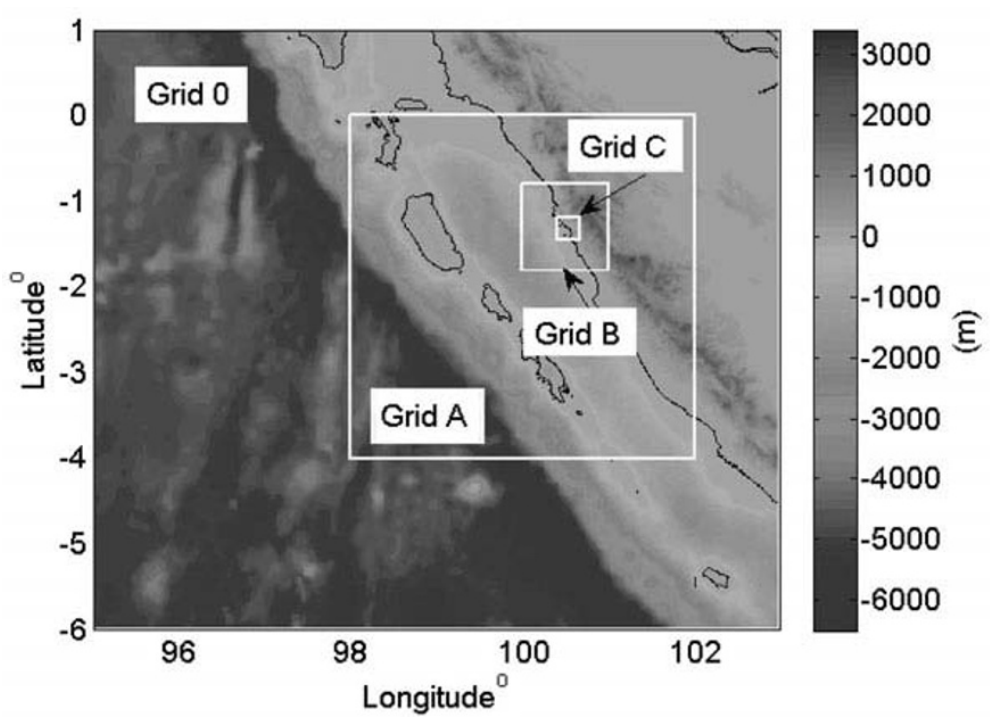

Fig. 3. Nested grids for COMCOT simulation domain.

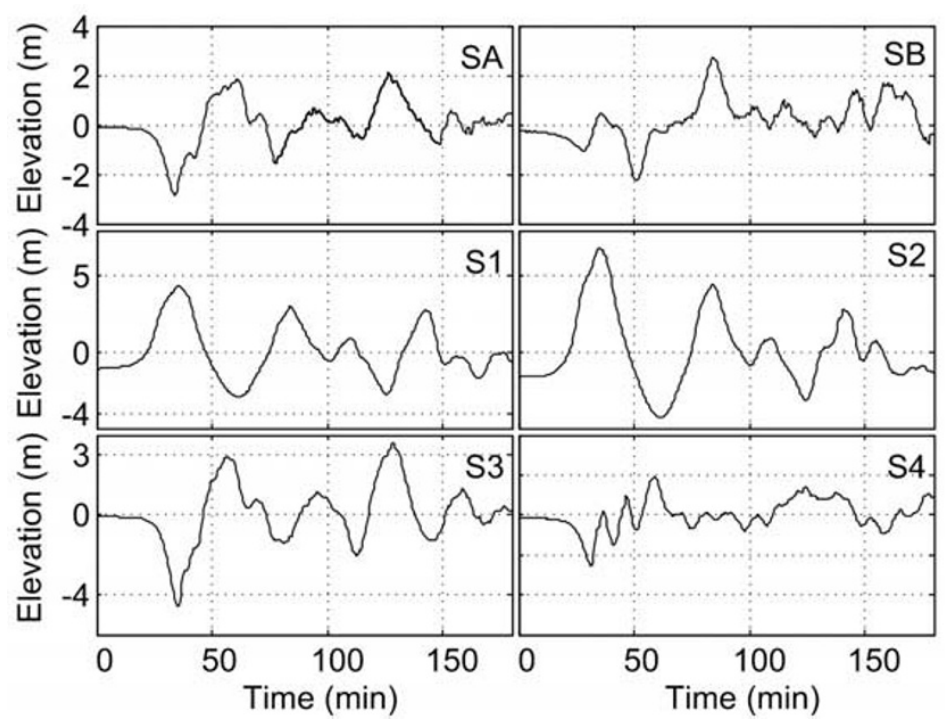

Fig. 4. The time series of the surface elevation (from COMCOT) at point P1 (shown in Fig. 1) on the open boundary.

ary were also linearly interpolated to a smaller time step of $0.1 \mathrm{~s}$. The innermost gird size used in all COMCOT simulations is $41 \mathrm{~m}$ in the bay area; the velocity and surface elevation provided by COMCOT are interpolated to a finer grid $(5 \mathrm{~m})$ on the offshore boundary for all sediment transport simulations. The condition that sediment can freely pass through the offshore boundary is achieved by requesting that the normal gradient of sediment concentration is 
Table 3. Accumulative percentages of grain size for sand samples collected from 5 locations.

\begin{tabular}{|c|rrrrr|}
\hline Class & $\begin{array}{c}\text { SP1 } \\
\text { Shoreline }\end{array}$ & $\begin{array}{c}\text { SP2 } \\
\text { Mid-tide }\end{array}$ & $\begin{array}{c}\text { SP3 } \\
\text { High tide }\end{array}$ & $\begin{array}{c}\text { SP4 } \\
\text { Inland }\end{array}$ & $\begin{array}{c}\text { SP5 } \\
\text { Breaker line }\end{array}$ \\
\hline$>2 \mathrm{~mm}$ & $0.00 \%$ & $0.00 \%$ & $0.00 \%$ & $2.42 \%$ & $0.53 \%$ \\
$>1 \mathrm{~mm}$ & $0.00 \%$ & $0.03 \%$ & $0.00 \%$ & $18.66 \%$ & $2.44 \%$ \\
$>0.5 \mathrm{~mm}$ & $0.03 \%$ & $0.43 \%$ & $0.19 \%$ & $46.37 \%$ & $27.18 \%$ \\
$>0.25 \mathrm{~mm}$ & $5.86 \%$ & $2.21 \%$ & $1.17 \%$ & $80.55 \%$ & $89.35 \%$ \\
$>0.125 \mathrm{~mm}$ & $94.35 \%$ & $63.01 \%$ & $28.65 \%$ & $98.61 \%$ & $99.53 \%$ \\
$>0.063 \mathrm{~mm}$ & $100.00 \%$ & $100.00 \%$ & $100.00 \%$ & $100.00 \%$ & $100.00 \%$ \\
\hline$d_{50}(\mathrm{~mm})$ & 0.18 & 0.14 & 0.10 & 0.46 & 0.39 \\
\hline
\end{tabular}

zero at the offshore boundary.

\subsection{Topography and bathymetry}

A relatively high resolution topography data set is needed for inundation and sediment transport simulations. The bathymetric and topographic data near-shore and onshore of Painan are derived from two data sets: (i) the SRTM topography data ${ }^{1}$ and (ii) the bathymetry and topography provided by USC Tsunami Research Center and GreenInfo Network (we shall call it USC-TRC data in this paper). The first set of data has a spatial resolution of $92 \mathrm{~m}$. The second data has a spatial resolution of about $200 \mathrm{~m}$ which combined 1:250,000 digitized nautical charts (1997-2004) with publicly available deep water bathymetry (SRTM30Plus). Borrero et al. (2006) used the second data set in their study of tsunami inundation modeling for western Sumatra. To prepare our bathymetric and topographic data, we first interpolated the bathymetric data from USC-TRC onto a $92.13 \mathrm{~m} \times 92.13 \mathrm{~m}$ grid using a bilinear method without gap filling; then we combined the SRTM topography data with the new $92 \mathrm{~m}$-USC-TRC bathymetric data to produce a uniform bathymetric and topographic data set with a spatial resolution of $92.13 \mathrm{~m}$. The digitized shoreline from nautical charts was adjusted manually for consistency with SRTM-water boundary; data gaps between the bathymetry and topography were interpolated and filled up with nautical charts. Since a finer grid is needed for predicting erosion and deposition maps, we further interpolated the bathymetric and topographic data onto a $5 \mathrm{~m} \times 5 \mathrm{~m}$ grid for sediment transport simulations.

To verify the topographic data and collect sand samples in Painan, we conducted a field survey in Painan and its neighbouring city Pariaman during August 18-23, 2010. We measured the slope of the shore face (between the water line and the high tide line) along the coast of Painan. We found that the slope of the shore face falls in the range of $1: 12$ and $1: 15$ and the typical width of the shore face is about $20 \mathrm{~m}$, giving us an elevation change of about $1.5 \mathrm{~m}$ from the water line to the high tide line. From the high tide line to the coastal road, the elevation change is about $1 \mathrm{~m}$. We conclude that the elevation change from the water line to the coastal road is about $2.5 \mathrm{~m}$, which is consistent with the topographic data we use for inundation simulations (see Fig. 7 and Fig. 8 for two typical beach profiles). Therefore, we believe that the accuracy of the topographic data we use is within $1 \mathrm{~m}$.

\footnotetext{
${ }^{1}$ The Shuttle Radar Topography Mission (SRTM) data has a horizontal resolution of 3 seconds or approximately 92 meters. The data is available at http://srtm.csi.cgiar.org/.
}

\subsection{Size distribution and composition of sand}

The Painan beach is about $1300 \mathrm{~m}$ long without major man-made structures, except a $60 \mathrm{~m}$ long, $100 \mathrm{~m}$ wide rubble mound platform in the northern part of the bay and a $110 \mathrm{~m}$ by $110 \mathrm{~m}$ sized seaport in the southern part of the bay. Figure 1 shows the five representative locations chosen for surface sand samplings in Painan; these locations include one point in the breaking zone (SP5), three points at the shore-face (mid-tide line) (SP1, SP2, SP3), and one point in the inland area (SP4). A grain-size analysis was conducted on all the collected sand samples according to the method described in Fork and Ward (1957). The sand samples from both Painan and Pariaman were analyzed, and the results for Painan are listed in Table 3: the sand in the breaker zone belongs to medium-size sand with a median grain size of about $0.4 \mathrm{~mm}$, and the sand in the shore face belongs to fine-size sand with a median grain-size of $0.15-$ $0.2 \mathrm{~mm}$. Our results agree with typical sediment grain-size distribution across the beach (Komar, 1976). The grain-size analysis of the sand samples collected at different depths onshore in Pariaman showed that the top layer was fine sand of $d_{50}=0.22 \mathrm{~mm}$ and the bottom layer was medium sand of $d_{50}=0.4 \mathrm{~mm}$. The top layer was approximately $0.35 \mathrm{~m}$ thick from the mid-tide line to the high-tide line. As no sand samples were taken beneath the surface layer in Painan beach, it is assumed in the present study that Painan beach has a vertical sediment structure similar to that of Pariaman.

Based on the surveyed data, a two-layer sand distribution model (Fig. 5) was assumed as the initial setting. The cement road near the shoreline is assumed non-erodible and the area between shoreline and the cement road is assumed erodible: the influences of the wooden houses on the sediment transport are ignored as these wooden houses can be easily smashed and swept by the strong tsunami waves (see Fig. 6 for the typical appearance of these wooden houses and the road). The simulated area is divided into 4 zones along the cross-shore direction. The boundary between zone- 1 and zone- 2 is chosen such that the local wave length of typical wind waves is about $90 \%$ of the deep water wave length and the bottom sand is not likely to be moved by the wind waves. The thickness of the top layer is $0.35 \mathrm{~m}$ and the thickness of the bottom layer is $4.65 \mathrm{~m}$. Medium sand $\left(d_{50}=0.4 \mathrm{~mm}\right)$ is used in the high wave energy zone for both the top and bottom layers; the width of this zone is $20 \mathrm{~m}$. In the region between the offshore boundary and the high wave energy zone, fine sand $\left(d_{50}=0.2 \mathrm{~mm}\right)$ was used for both the top and bottom layers. In the shore-face zone (width $=20 \mathrm{~m}$ ), fine sand was used for the top layer 


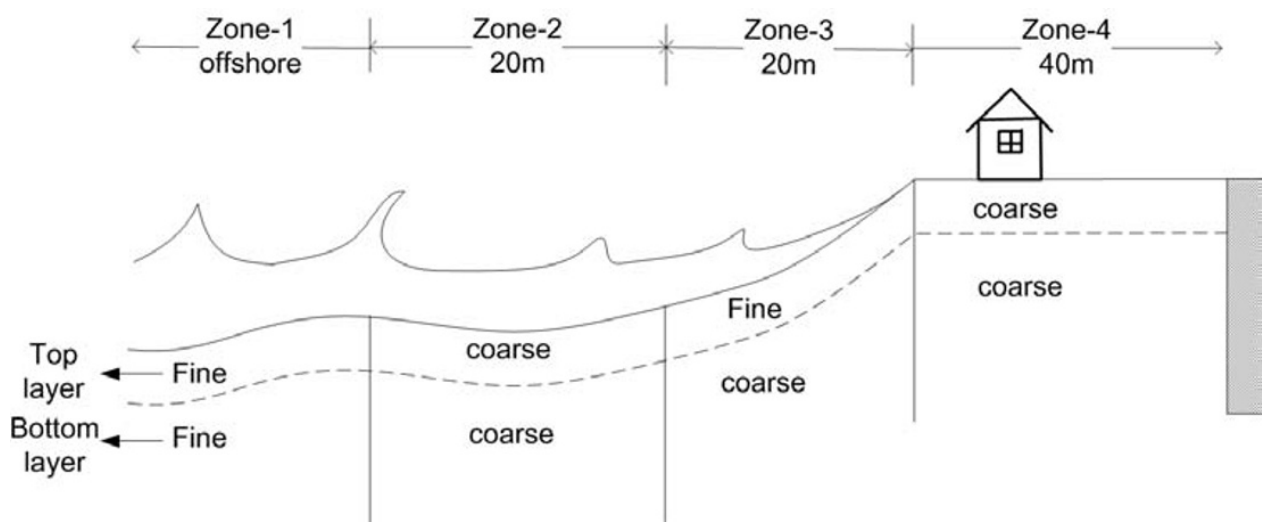

Fig. 5. The initial sand distribution (not drawn to scale).

(a)

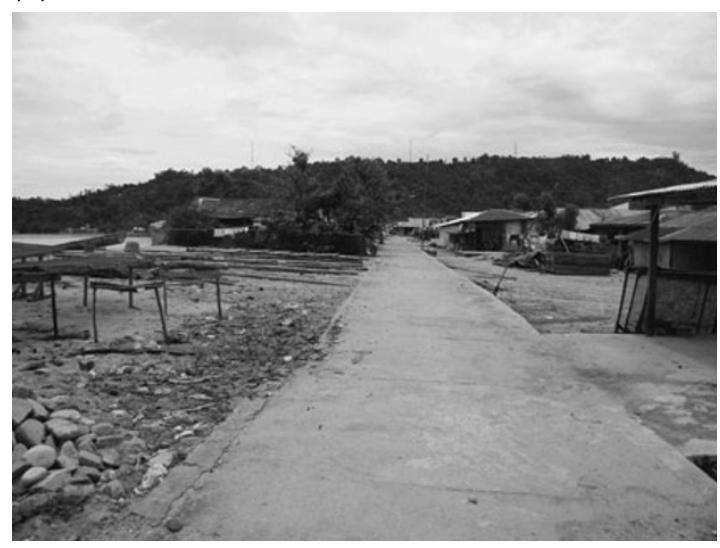

(b)

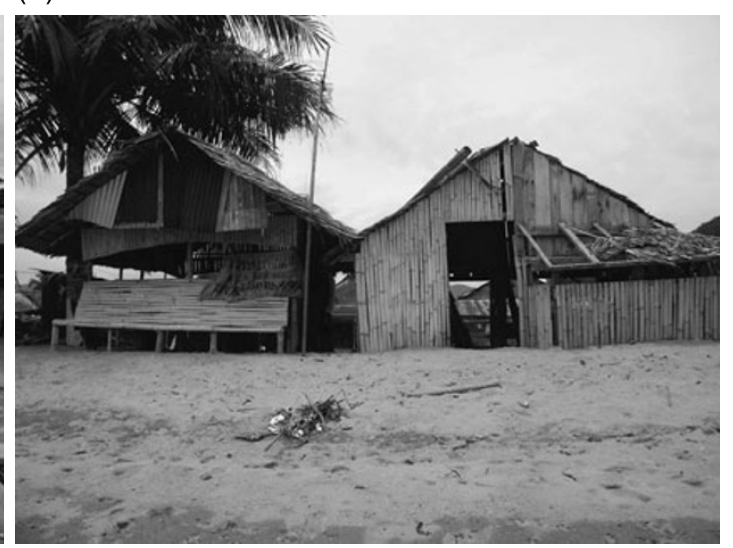

Fig. 6. Houses and the road near the Painan beach. Left: A cement road about $5 \mathrm{~m}$ wide approximately parallel to the shoreline. The distance between the shoreline and the road is about $60 \mathrm{~m}$. Right: Wooden houses with iron roofs just behind the high-tide line.

and medium sand was used for the bottom layer. In the region (width $=40 \mathrm{~m}$ ) between the shore-face and the cement road, medium sand was used for both the top and bottom layers. The city area, seaport and stone platform were all considered to be non-erodible.

\section{Results and Discussion \\ 4.1 Inundation maps}

Table 4 summarizes the arrival time of the first wave peak, tsunami height along the shoreline, and inundation distance in the city area of all the simulated scenarios. The differences among these 6 scenarios are notable. The calculated maximum tsunami heights along the shoreline are $2.6 \mathrm{~m}, 3.5 \mathrm{~m}, 3.9 \mathrm{~m}$ and $3.4 \mathrm{~m}$ for SA, SB, S3 and S4, respectively. These tsunami heights would cause only moderate flooding in the city area with a maximum inundation distance of $570 \mathrm{~m}$ for S3. While for other two scenarios S1 and S2, severe flooding would happen in the city area, resulting in maximum inundation distances $1433 \mathrm{~m}$ and $1842 \mathrm{~m}$, respectively. We remark that for the $\mathrm{S} 2$, the whole Painan city would be submerged. The significant differences among the simulated scenarios highlight the dramatic effects of slip distribution and sea floor deformation. For scenarios SA, $\mathrm{SB}, \mathrm{S} 3$ and S4, the high-slip regions locate in the seaward of Mentawai islands. The displaced seawater would have to pass through the barrier islands before reaching the Sumatran mainland; much of the tsunami energy would be dissipated during the wave propagation process. On the other hand, for S1 and S2, a large portion of the high slip region exists in the Mentawai strait, leaving the coastal area of west Sumatra exposed directly to the tsunami waves. Moreover, the subsidence along the Sumatran mainland would allow tsunami waves to penetrate further inland, causing more damage and flooding than other scenarios. These phenomena were also discussed by Borrero et al. (2006) and McCloskey et al. (2008).

After comparing the simulated tsunami wave heights and inundation distances for all scenarios, we found that scenario S2 is the worst case scenario. The inundation map for $\mathrm{S} 2$ is shown in Fig. 7, where variations of the inundation depth along two cross-sections are also shown. Scenario S3 represents a typical scenario of negative leading wave. The inundation map for S3 is shown in Fig. 8, where variations of the inundation depth along two cross-sections are also shown. These two scenarios are chosen to further study the hydrodynamics, sediment transport and shoreline changes.

For S2, the first wave front would reach the coast of Painan about 26 minutes after the rupture, with an initial set-down of water surface before the peak. The initial setdown of the surface elevation is because of the subsidence 
Table 4. The simulated inundation parameters for 6 scenarios in Painan.

\begin{tabular}{ccccc}
\hline Scenario & $\begin{array}{c}\text { Arrival time of } \\
\text { first crest } \\
(\mathrm{min})\end{array}$ & $\begin{array}{c}\text { Arrival time of } \\
\text { first wave trough } \\
(\mathrm{min})\end{array}$ & $\begin{array}{c}\text { Water surface elevation } \\
\text { along shoreline } \\
(\mathrm{m})\end{array}$ & $\begin{array}{c}\text { Maximum inundation } \\
\text { distance } \\
(\mathrm{m})\end{array}$ \\
\hline SA & $/$ & 35 & $2.3-2.6$ & 152 \\
SB & $/$ & 36 & $3.3-3.5$ & 508 \\
S1 & 36 & $/$ & $4.6-4.9$ & 1433 \\
S2 & 36 & $/$ & $6.7-7.0$ & 1842 \\
S3 & $/$ & 38 & $3.5-3.9$ & 570 \\
S4 & $/$ & 37 & $2.5-3.4$ & 222 \\
\hline
\end{tabular}

(a)

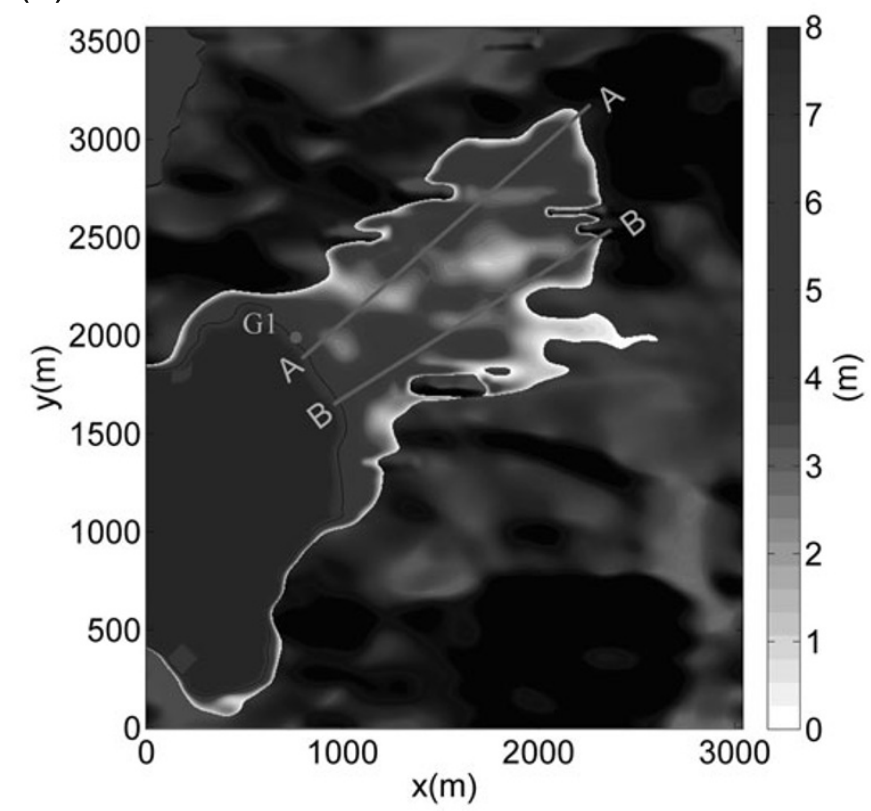

(b)
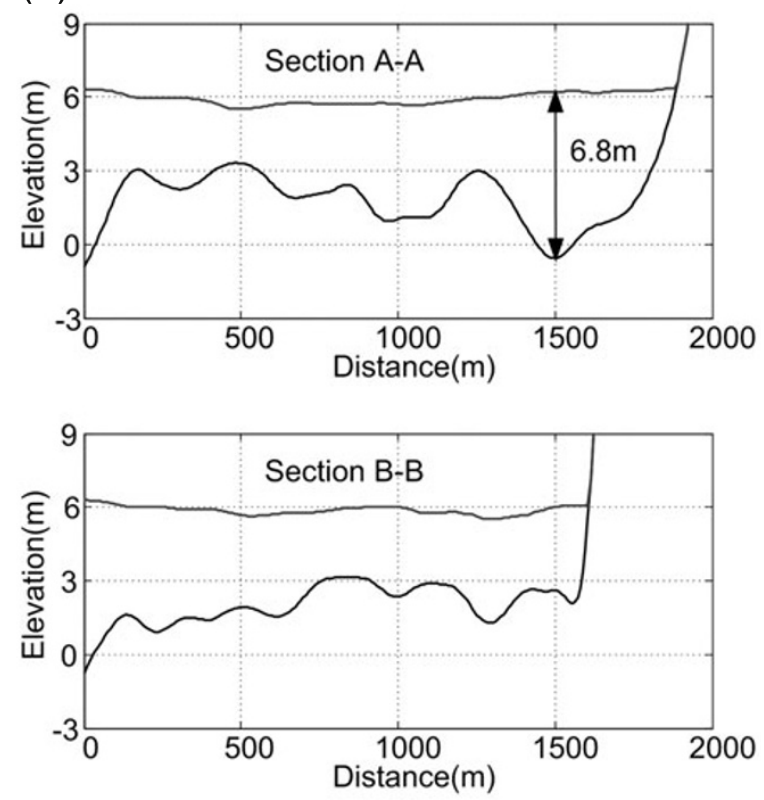

Fig. 7. Left: Map of the maximum inundation depth $(\mathrm{m})$ in Painan city for Scenario S2; Right: water surface and topography in section A-A and section B-B.

in the coastal area (Fig. 4). Figure 7 shows a map of the maximum flow depth during the first three hours of tsunami wave attack: the entire city would be inundated with a maximum tsunami inundation depth of about $6.8 \mathrm{~m}$ in the city area. Within the first three hours, three main peak waves could reach the Painan bay area: the first peak wave might hit the shoreline 37 minutes after the rupture, raise the water surface up to $7 \mathrm{~m}$ at the shoreline and penetrate $1884 \mathrm{~m}$ inland within 14 minutes. The average inundation depth is about 3-4 $\mathrm{m}$ in the city area and the maximum inundation depth occurs in the northeast part of the city, where the elevation is relatively low. According to Shuto (1993), when the inundation depth is larger than $2 \mathrm{~m}$, wooden house will be completely washed away. Thus the wooden houses near the high-tide line would be swept away, producing a large amount of floating debris. The average speed of the wave front could be about $2 \mathrm{~m} / \mathrm{s}$, and the inundation flow velocities may reach about $5 \mathrm{~m} / \mathrm{s}$ which are large enough to erode a large amount of sediment near the shoreline. Bearing in mind that we have not considered the city buildings in the simulations; if the effects of buildings were considered, the maximum flow speed within constrained streets may be faster than $5 \mathrm{~m} / \mathrm{s}$ due to the channelling effects (Borrero, 2005).

\subsection{Sediment transport for scenario S2}

4.2.1 Erosion and deposition Nine instants are indicated in Fig. 9 at which nine snapshots are taken to show suspended sediment concentration covering the water flooding and retreating processes for S2 (Fig. 10(a)(i)). When the first tsunami wave front approaches the shoreline at 26 minutes after the rupture, the sediment concentration increases rapidly near the wave front. The highly erosive wave front would suspend a large volume of sand, resulting in a maximum sediment concentration more than $100 \mathrm{~kg} / \mathrm{m}^{3}$. These kinds of high concentration sediment-laden waves have been observed and depicted by many tsunami witnesses or satellite images (Narayana et al., 2007; Brooks, 2010). The concentration of suspended sediment could be as large as $100 \mathrm{~kg} / \mathrm{m}^{3}$, which is similar to that in the hyper-concentration flows observed in Yellow River in China (Chien and Wan, 1999). The sediment concentration would decrease as the flow velocity decreases from 26 minutes to 40 minutes after the rupture, and a portion of the suspended sand would be deposited in the city 
(a)

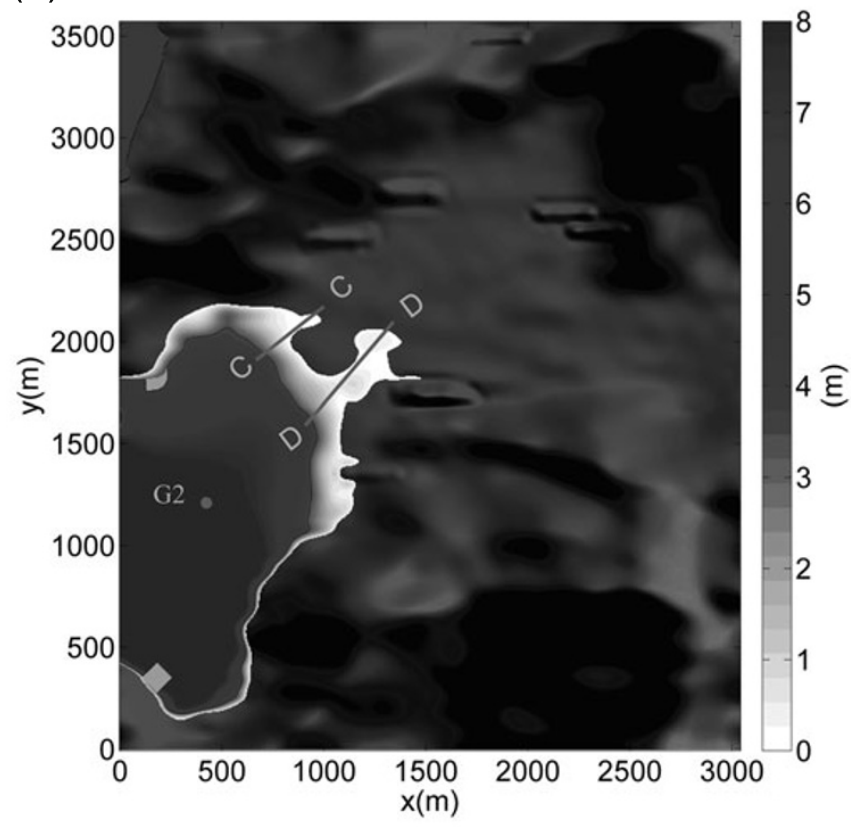

(b)
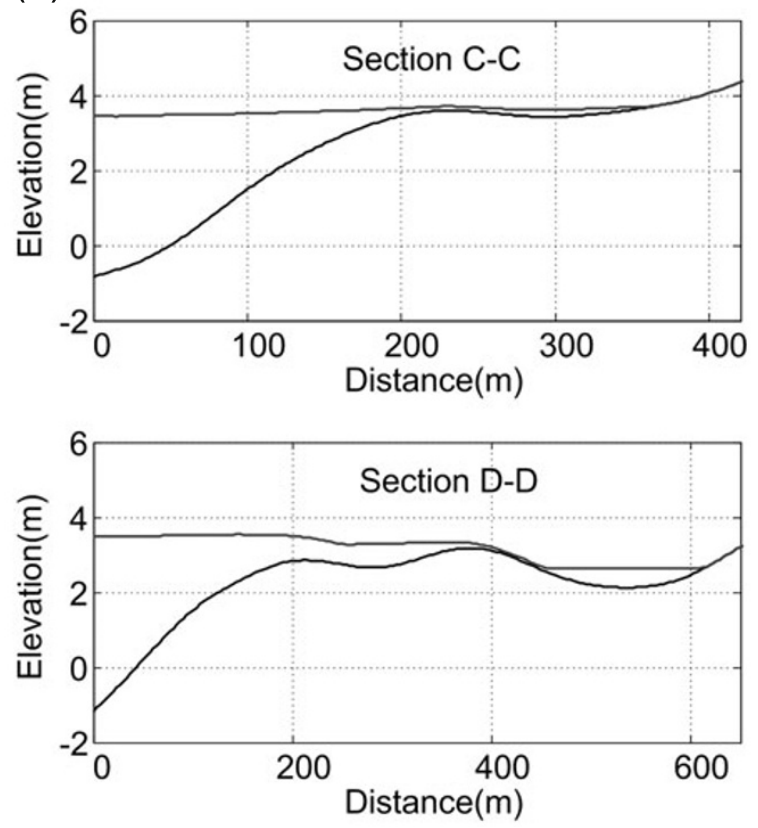

Fig. 8. Left: Map of the maximum inundation depth $(\mathrm{m})$ in Painan city for Scenario S3; Right: water surface and topography in section C-C and section D-D.
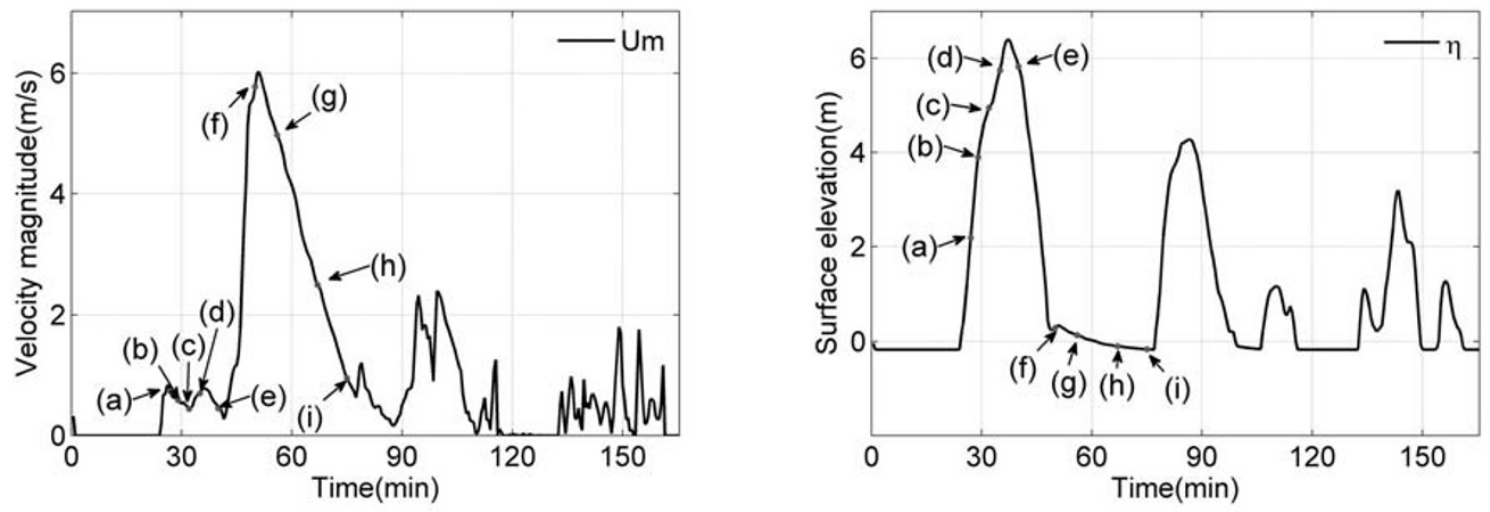

Fig. 9. Time series of velocity magnitude (left) and surface elevation (right) at point G1 (see Fig. 7). The labels (a)-(i) refer to the times at which the snapshots are taken of the concentration of the suspended sand in the flooding water.

area. About 40 minutes after the rupture, the flooding water reaches the maximum run-up and the flooding water in the city area starts retreating. Channeled backwash flows, which tend to follow the coastal morphology since they are mainly driven by gravity, can be more erosive and powerful than channeled run-up flows. The strong backwash flows could transport seaward a large amount of debris eroded from shoreward areas. About 1 hour 15 minutes after the rupture the concentration of suspended sediment becomes almost zero in both the city and bay areas.

Significant sediment transport may occur near the shoreline during the water retreating period, resulting in a net erosion of the shore face and severe scour in the region adjacent to the seaward side of the road base (see Fig. 11). The most severe erosion would be found in the southern part of the beach where the elevation is relatively low and the chan- neled retreating flow may form. After three hours, most of the eroded sand would be transported off-shore to the active coastal zone by the backwash flow, resulting in a maximum deposition depth of $1.0 \mathrm{~m}$ in the bay area (see Fig. 11). This phenomena is consistent with the bathymetric surveys conducted at Kuala Meurisi (a site about $100 \mathrm{~km}$ south of Banda Aceh) following the 2004 tsunami in which a large offshore bar was observed (Gelfenbaum et al., 2007). Apotsos et al. (2011) attributed the formation of large offshore bars to collisions of the backwash flows and the up-rushing waves. A thin layer (about 5-30 cm thick) of sediment could be deposited in the city area, and a maximum scour depth of nearly $5 \mathrm{~m}$ might occur on the seaward side of the road, which is caused by the abrupt change of the erodible and non-erodible beach materials. 

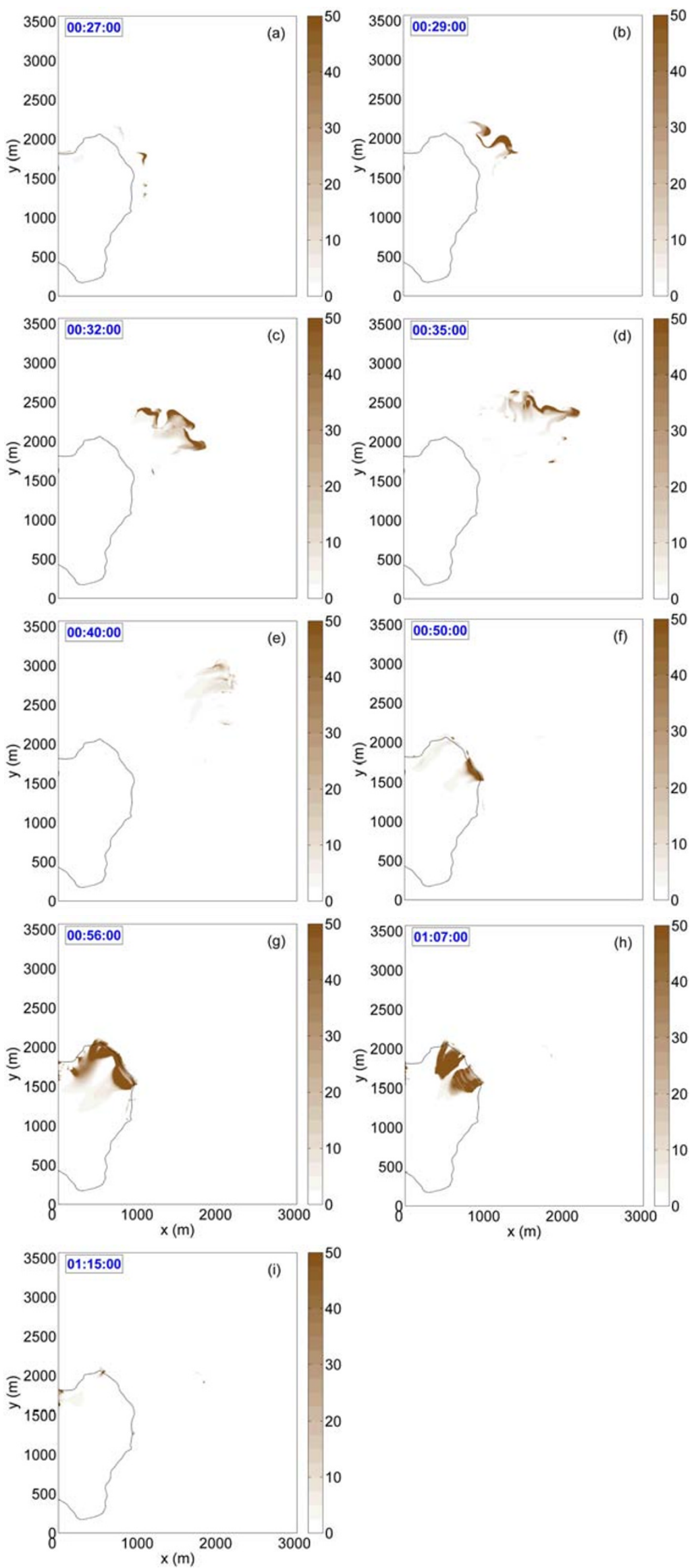

Fig. 10. Snapshots of suspended sediment concentration $\left(\mathrm{kg} / \mathrm{m}^{3}\right)$ during the first 1.5 hours. Concentration greater than $50 \mathrm{~kg} / \mathrm{m}^{3}$ are not resolved. 

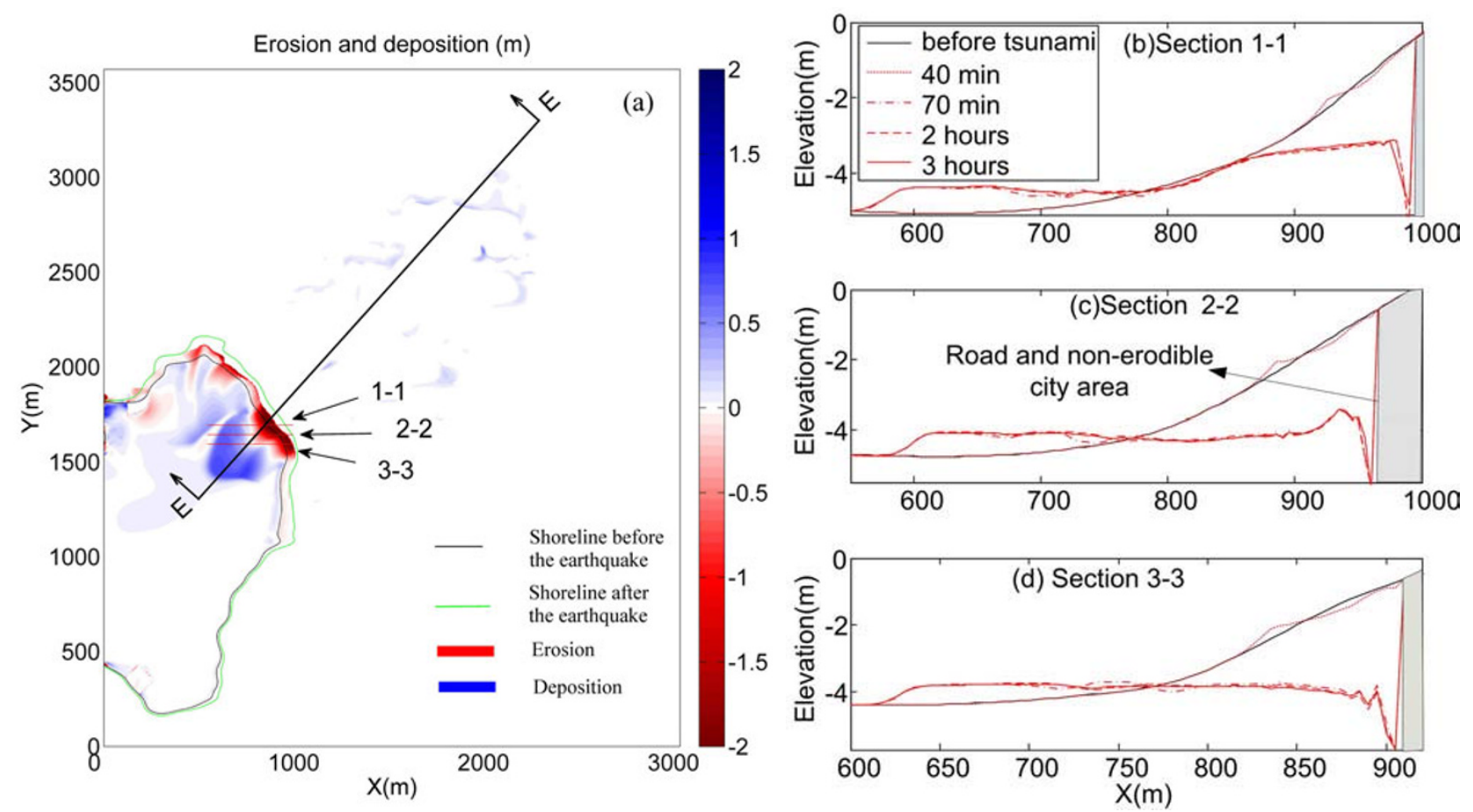

Fig. 11. (a) Map of erosion and deposition areas (color bar indicates the erosion (negative) and deposition (positive) depth (m)); (b) Bed profile change in section 1-1; (c) Bed profile change in section 2-2; (d) Bed profile change in section 3-3.

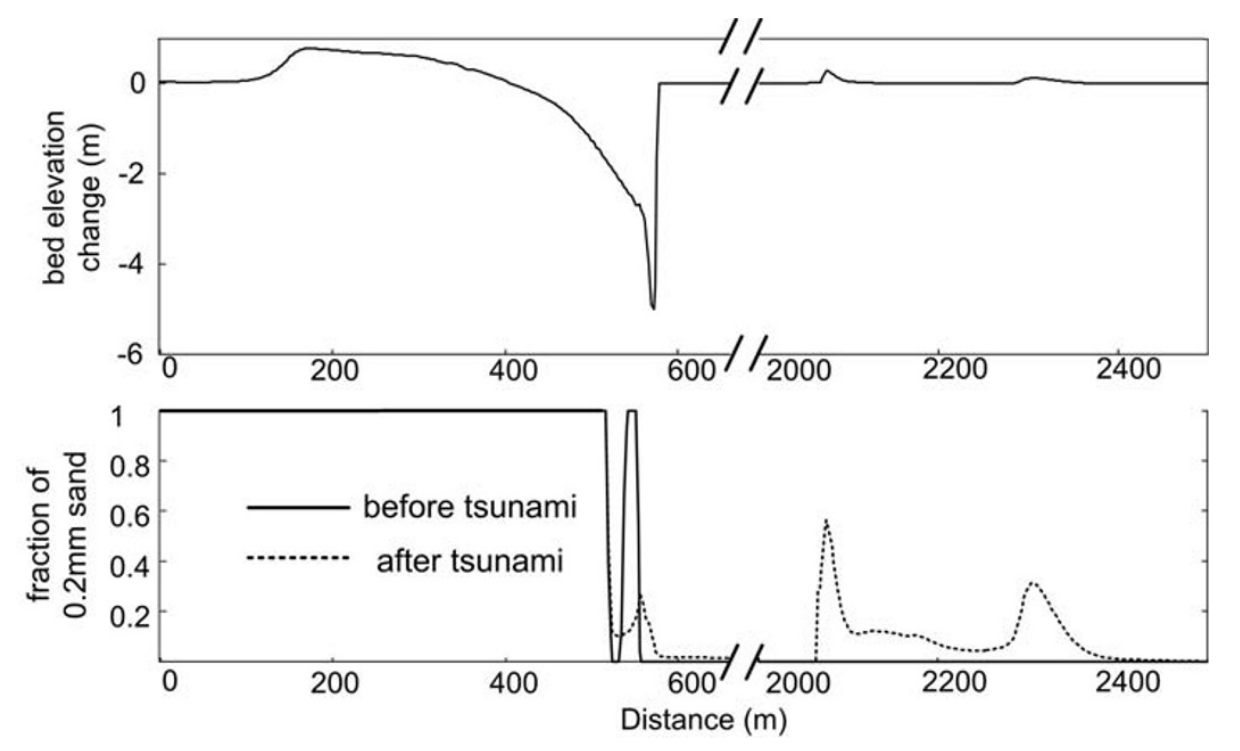

Fig. 12. Upper: bed elevation change for section E-E; Lower: the fraction of $0.2 \mathrm{~mm}$ sand along section E-E for S2. A value of 1 corresponds to $100 \%$ of fine sand $(0.2 \mathrm{~mm})$, a value of 0.5 corresponds to $50 \%$ of fine sand and $50 \%$ of medium sand, a value of 0 corresponds to $100 \%$ of medium sand $(0.4 \mathrm{~mm})$.

4.2.2 Scouring around the road and the seaport Scour damage is one of the main factors leading to the destruction of coastal infrastructure, such as building foundations, roadways, jetties and other coastal structures (Maheshwari et al., 2006; Paris et al., 2009). During the 1960 Chilean Tsunami, a quay wall in Hachinohe Port and a jetty in Kesen-numa bay were destroyed because the foot of the jetty were eroded as deep as $10 \mathrm{~m}$ (Takahashi et al., 2000). The scour depth greater than $2 \mathrm{~m}$ were also at- tested by many road failures found in south Lhok Nga, Indonesia (Paris et al., 2009) and Kamala, Phuket, Thailand (Lukkunaprasit and Ruangrassamee, 2008) during the 2004 Indian ocean tsunami. In our simulations, a scour trench with a maximum depth of nearly $5 \mathrm{~m}$ is formed at the toe of the roadway foundation (Fig. 12), which may ultimately lead to a collapse of the road since the non-erodible depth (road foundation) is normally on the order of $1 \mathrm{~m}$. The collapse of the shoreline road would significantly hamper the 

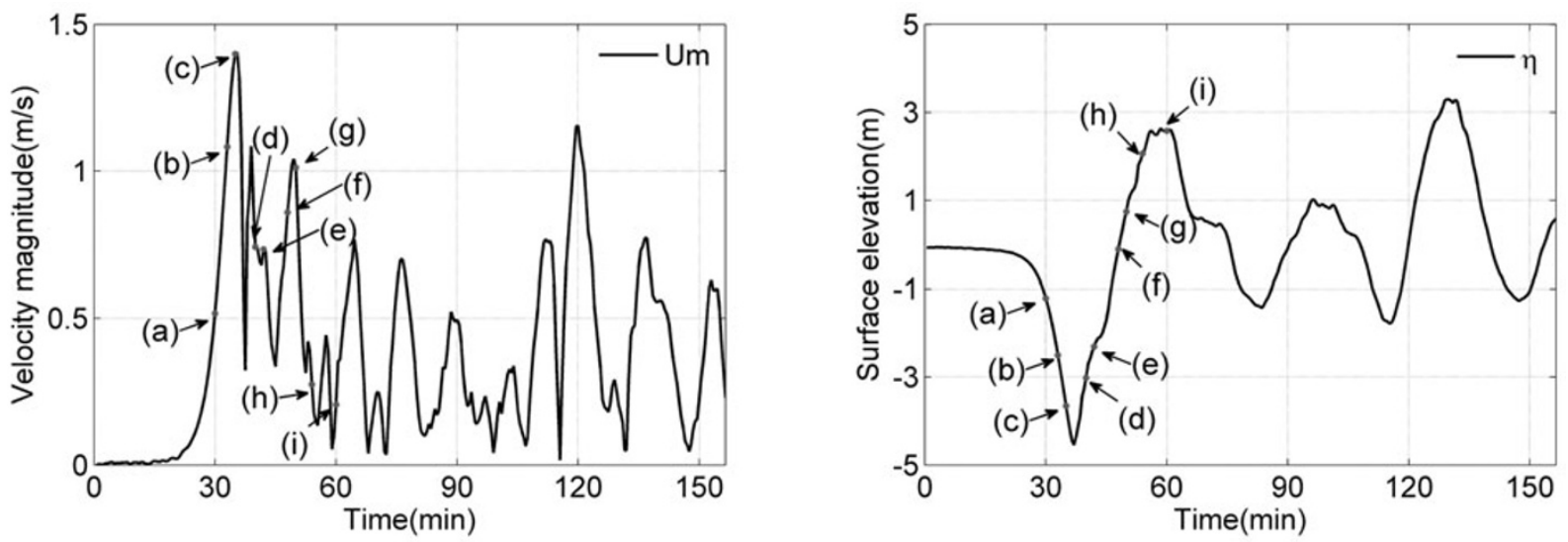

Fig. 13. Time series of velocity magnitude (left) and surface elevation (right) at point G2 (see Fig. 8). The labels (a)-(i) refer to the times at which the snapshots are taken of the concentration of the suspended sand in the flooding water.

post-tsunami relief and rescue work. Our simulations also show that significant scour occurs in the immediate vicinity of the stone platform located in the north side of the bay with the maximum scour depth exceeding $1 \mathrm{~m}$.

It is realized that the scouring induced by tsunamis is different from the present understanding of scour processes in a river or coastal environment around bridge piers (Kato et al., 2000; Nakamura et al., 2008). Tsunami waves are very long waves and tsunami flows are far from steady and uniform. For tsunami flows, scouring occurs often within less than 1 hour. Some experimental and numerical studies have been done to understand the tsunami-induced scours around coastal structures (Kato et al., 2001; Tonkin et al., 2003; Nakamura et al., 2008), and it is revealed that most rapid scour on sand substrate occurred at the tsunami downrush stage.

4.2.3 Characteristics of tsunami deposits One way to study the historical tsunami is to examine the characteristics (e.g., grain size distribution) of the tsunami deposits onshore (Shi et al., 1995; Dawson et al., 1996; Gelfenbaum and Jaffe, 2003; Moore et al., 2007; Paris et al., 2007). When analyzing tsunami deposits, it is important to know the origin of the sediments in a core sample and to relate the tsunami deposits to the flooding and retreating process during a tsunami event. Figure 12 shows the change of bed profile and the change of sand fraction in the upper layer along the cross-section E-E in Fig. 11. After the attack of the tsunami, due to the severe erosion in the shore-face, the fine sand in the shore-face could be moved, exposing the bottom sand layer to the water above. A large amount of fine sand and part of medium sand could be deposited in the bay area, however, no significant change in the sand fraction can be observed in the bay area. Some of the sand deposited in several places in the city areas may come from the bay and the shore-face areas, and it is possible to examine the sediment cores in these places to investigate the historical tsunamis from tsunami deposits (Bourgeois, 2009).

4.2.4 Remarks on equilibrium sediment concentration and settling velocity In addition to the van Rijn's formula, we have also tested the Bagnold's formula (1966) and Ackers-White's formula (1973) for the equilibrium sed- iment concentration (the detailed comparison is not shown here). The erosion and deposition patterns obtained by these three formulas are generally similar: the erosion depth predicted by van Rijn's formula is between those predicted by Ackers-White's formula and Bagnold's formula. Our simulated erosion and deposition depths are quantitatively reasonable even though the hindered settling effects are not considered. This could also be evaluated through the measured data during the post-tsunami field surveys (Gelfenbaum and Jaffe, 2003; Narayana et al., 2007; Srinivasalu et al., 2007; Pari et al., 2008). However, the maximum sediment concentration could reach more than 800 $\mathrm{kg} / \mathrm{m}^{3}$ in several spots during a short period of time; there is a concern that the high suspended sediment concentration may hinder the settling of sediment grains (van Rijn, 2007). We have evaluated the effect of hindered settling by using the modified settling velocity $w_{s}=\left(1-c_{s}^{\text {tot }} / c_{d}\right)^{5} w_{s, 0}$, where $w_{s, 0}$ is the original settling velocity, $c_{s}^{\text {tot }}$ is the total mass concentration of suspended sediment in the water column and $c_{d}$ is a reference density (Richardson and Zaki, 1954). We took $c_{d}=1600 \mathrm{~kg} / \mathrm{m}^{3}$ in this exercise. For a uniform concentration of $50 \mathrm{~kg} / \mathrm{m}^{3}$ during the entire inundation period, the hindered settling velocity would be reduced by less than $15 \%$ relative to the original settling velocity. For the scenario $\mathrm{S} 2$, the concentration of suspended sand is less than $50 \mathrm{~kg} / \mathrm{m}^{3}$ most of the time during inundation period; high concentration region may be found only near the shoreline (see Fig. 10). Our simulation shows that the modified settling velocity does not cause noticeable changes in the deposit thickness or the scour depth; our results are consistent with those of Apotsos et al. (2011), who considered the combined effects of hindered settling and stratification. However, for 3D models, Apotsos et al. (2011) found the significant influence of hindered settling velocity on the deposit thickness if the mixing of sediment into water was not reduced by the density stratification due to the high concentration of suspended sediment.

\subsection{Hydrodynamics and sediment transport for sce- nario $\mathrm{S3}$}

We examine scenario S3 in Table 4, which has a negative leading wave. As shown in Fig. 8, this scenario may cause 

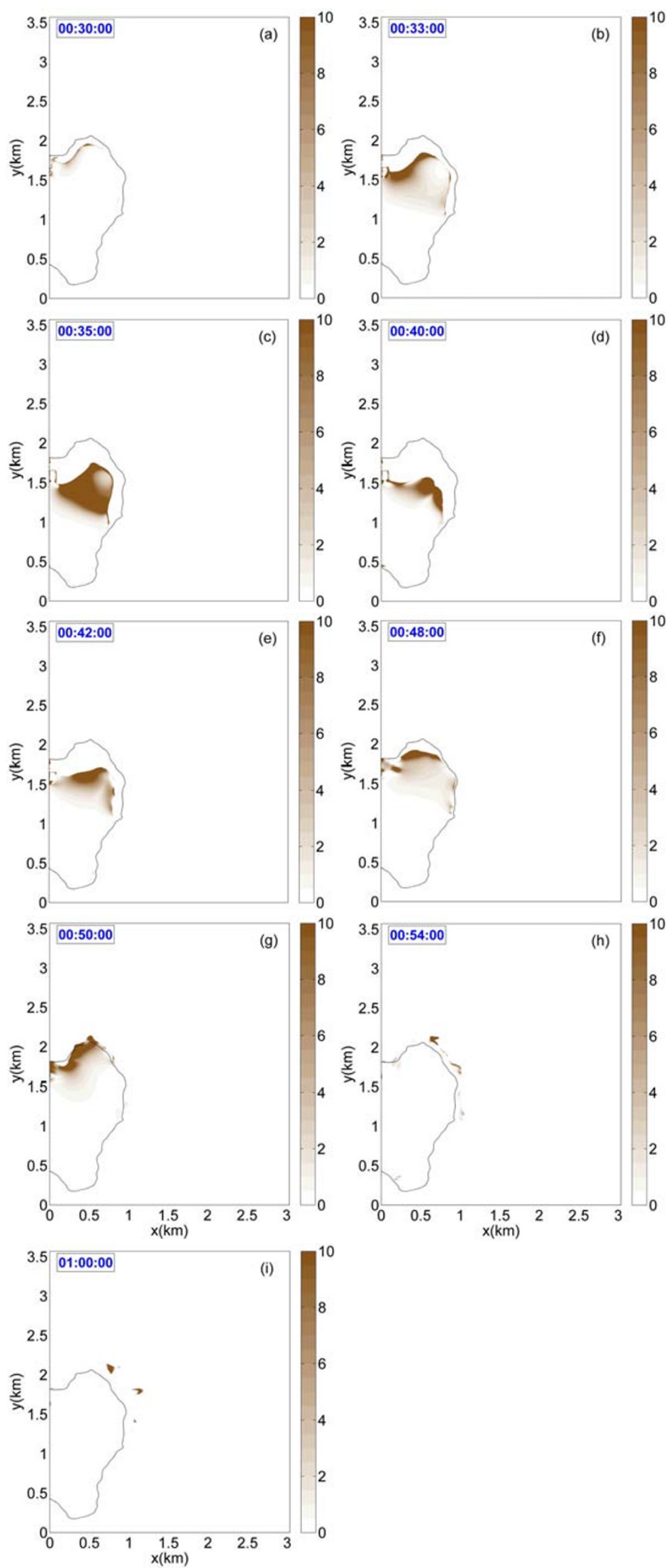

Fig. 14. Snapshots of suspended sediment concentration $\left(\mathrm{kg} / \mathrm{m}^{3}\right)$ during the first 1 hours. Concentration greater than $10 \mathrm{~kg} / \mathrm{m}^{3}$ are not resolved. 
(a)

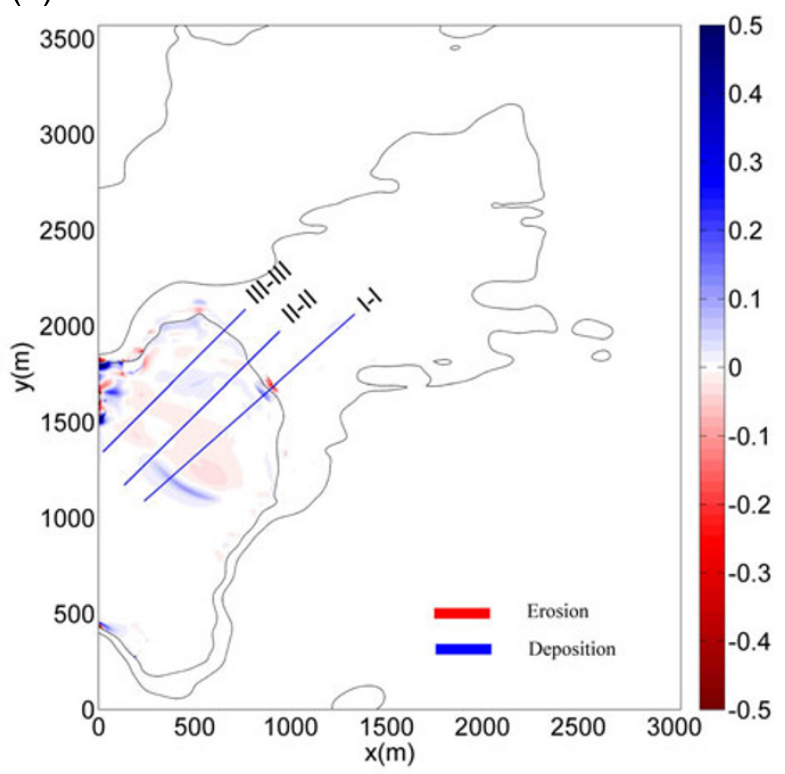

(b)

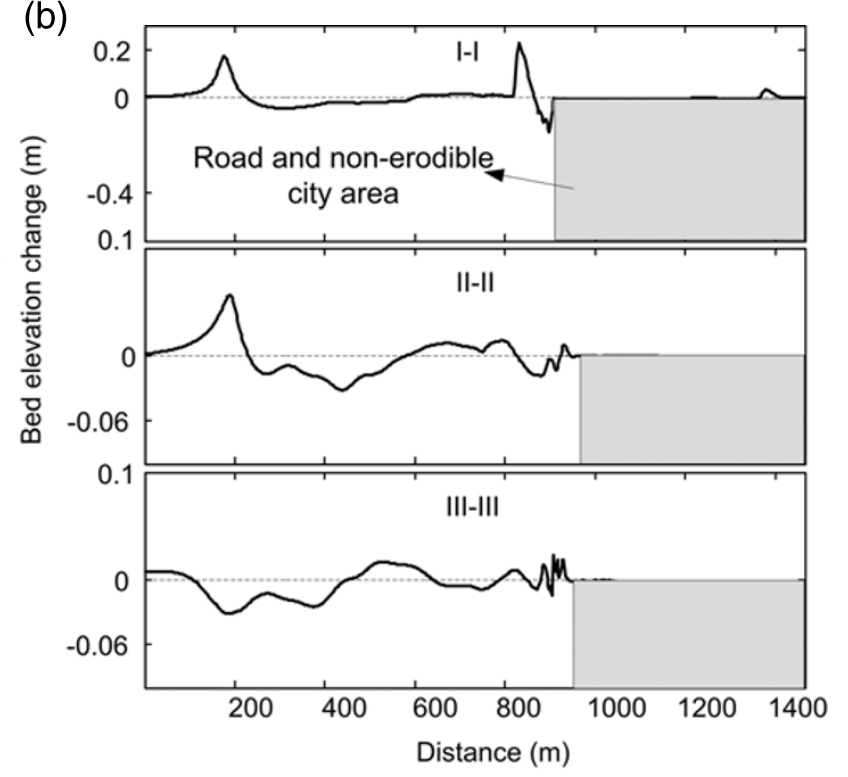

Fig. 15. Left: erosion and deposition map for S3; Right: bed elevation change for cross-sections I-I, II-II, III-III.
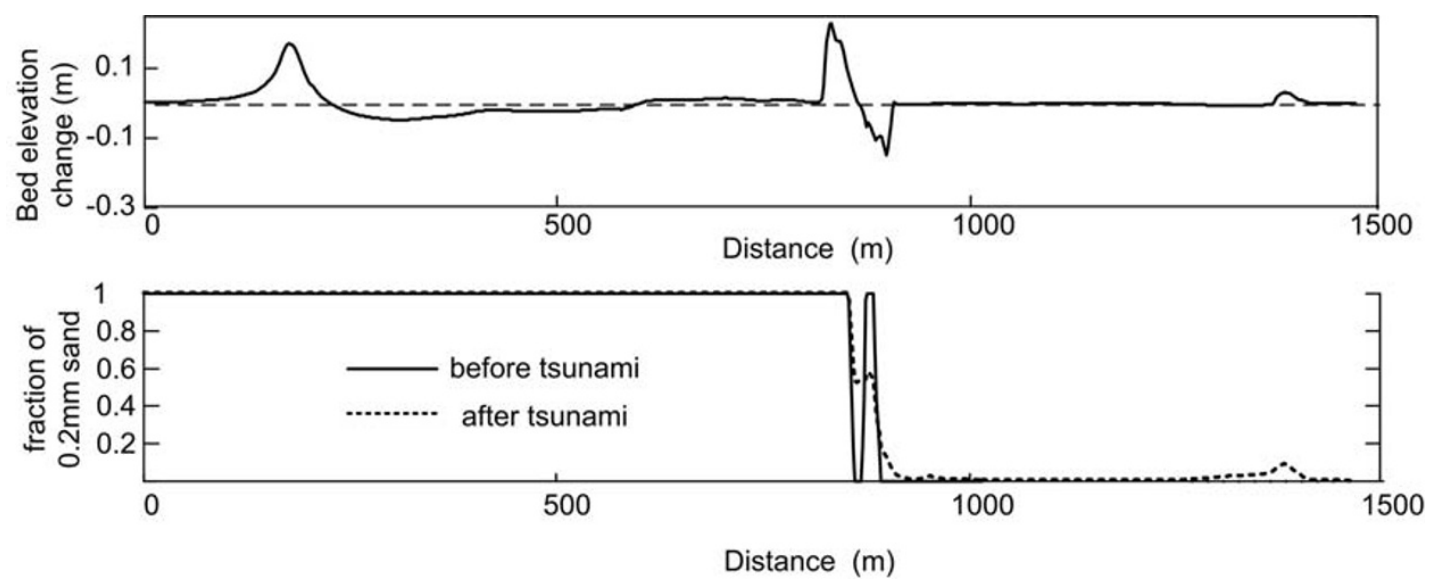

Fig. 16. Upper: bed elevation change for section E-E; Lower: the fraction of $0.2 \mathrm{~mm}$ sand along section E-E for S2. A value of 1 corresponds to $100 \%$ of fine sand $(0.2 \mathrm{~mm})$, a value of 0.5 corresponds to $50 \%$ of fine sand and $50 \%$ of medium sand, a value of 0 corresponds to $100 \%$ of medium sand $(0.4 \mathrm{~mm})$.

a moderate inundation in Painan. In scenario S3, a large amount of seawater in the bay would retreat seaward in the first 35 minutes, exposing nearly $500 \mathrm{~m}$ wide original seafloor to the air before the arriving of the first positive wave. During the retreating period, a considerable amount of sediment would be suspended and transported seaward. Figure 13 shows the time series of velocity magnitude and surface elevation at point G2 (see Fig. 8) with nine instants indicating at which the snapshots of the concentration of suspended sediment are taken (Fig. 14). Erosion would occur in the north part of Painan Bay as the bathymetry is shallower in this area. When the first peak wave penetrates in the Bay, it would collide with the first receding wave and some of the suspended sediment would be deposited locally as the flow velocity abruptly decreases. The peak wave would first fill up the northern part of the bay area before it could inundate inland. Some sediment would be eroded by the passing wave-front while the amount of suspended sediment is noticeably less in the inland area than in the north Bay area. Limited flooding would occur near the shoreline area which causes weak backwash flow and little scour near the road. Unlike the severe erosion and scour occurs near the shoreline in scenario S2, the most severe erosion happens in the offshore area with a larger extent due to the first retreating wave. Moreover, two separate deposition areas could be observed in the further offshore area and near the shoreline area. These depositions are all generated by the collision of onrush wave and retreating wave but in different phases (Fig. 15).

According to the change of the bed profile and the change of the sand fraction along the cross-section I-I (see Fig. 16), the deposition near the shoreline is composed of fine sand. 
The sand source should come from the shore-face which can be easily inferred from the hydrodynamic process and the resulting distribution of sand fraction. The fine sand in the shore-face has been moved to the seaward and mixed with the medium sand from either the high wave energy area or the house base area. Very little deposition could be observed in the city area except a small patch near the limit line of runup. Similar to S2, the deposition is mainly medium sand. The morphological change is moderate compared with scenario S2. But it is hard to conclude that the leading depression wave form would cause slighter sediment movement than the leading positive one since the magnitude of the hydrodynamic parameters for these two scenarios are different (e.g. wave heights, wave lengths). Though some investigations (Kobayashi and Lawrence, 2004; Apotsos et al., 2011) claimed that the leading depression wave would cause little erosion during retreating stage of first wave. Meanwhile, smaller runup and weaker backwash flow would cause less sediment movement. The difference of the erosion and deposition pattern between these two scenarios provides very helpful information in the selection of drilling sites for core samples in investigation of historical and prehistoric tsunami deposits.

\section{Summary}

Six rupture models with magnitude ranging from $M_{\mathrm{w}}=$ 8.7 to $M_{\mathrm{w}}=8.92$ have been considered in this study to assess the tsunami inundation and sediment transport in Painan, West Sumatra, Indonesia. According to the worst scenario, Painan would be hit by the first tsunami wave about 26 minutes after the rupture, and the tsunami could cause a maximum inundation depth of about $6.8 \mathrm{~m}$ and a maximum inundation distance about $1884 \mathrm{~m}$, with an average inundation depth of about 3-4 $\mathrm{m}$ in the city area. Sediment transport caused by the tsunami waves has also been examined for two representative scenarios: one has a positive leading wave and the other has a negative leading wave. For the case of a positive leading tsunami wave, a large amount of sediment would be suspended near the shoreline during the backwash stage and the suspended sediment would be deposited in the offshore area forming a large sandbar near the shoreline. A considerable amount of sediment would be suspended by the passing wave front and leaving behind a small amount deposition in the city area. The foundation of a shore-parallel road could be severely eroded by the backwash flows. For the case of a negative leading tsunami wave, significant sediment movement would occur during the backwash stage accompanying the negative peak wave; an offshore sandbar could form in the bay area, while no noticeable large area of sand deposit could be found in the city area. The difference of the erosion and deposition patterns between these two scenarios provides useful information for tsunami geologists to further study the paleo-tsunami in this area.

Acknowledgments. This work has been supported by the Earth Observatory of Singapore (EOS), Nanyang Technological University, Singapore, through the project "Tsunami Hazard Mitigation for West Sumatra". The authors would like to thank the following colleagues at the Earth Observatory of Singapore: Dr. Kusnowidjaja Megawati for arranging our survey trips; Dr. Adam D. Switzer and Miss Lee Yingsin for providing the facilities for the grain-size analysis. We also thank the two anonymous reviewers for their constructive comments and suggestions, which have greatly improved the quality of the manuscript. This is EOS contribution No. 17

\section{Appendix A. Expressions for Adaptation Time $T_{S}$ and Equilibrium Sediment Concen- tration $C_{\text {eq }}$}

This appendix summarizes the empirical formula for the adaptation time and the equilibrium sediment concentration used in XBeach. The purpose is to explain how some of the important model parameters were chosen in our simulations. The adaptation time $T_{s}$ (unit: $\mathrm{s}$ ) is determined by the local water depth $h$, sediment fall velocity $w_{s}$, and a sediment transport depth factor $f_{T_{s}}$ :

$$
T_{s}=\max \left(f_{T_{s}} \frac{h}{w_{s}}, 0.2\right)
$$

The formula for sediment fall velocity in XBeach is proposed by Ahrens's (2000)

$$
\begin{aligned}
& w_{s}=C_{1}(s-1) g d_{50}^{2} / v+C_{t} \sqrt{(s-1) g d_{50}} \\
& C_{1}=0.055 \tanh \left(12 A^{-0.59} \exp (-0.0004 A)\right) \\
& C_{t}=1.06 \tanh \left(0.016 A^{0.50} \exp (-120 / A)\right)
\end{aligned}
$$

where $A=(s-1) g d_{50}^{3} / v^{2}, A$ is Archimedes buoyancy index, $s=\rho_{s} / \rho$ is specific gravity. $v$ is kinematic viscosity coefficient, $d_{50}$ is the median grain size, $d_{90}$ is defined as the grain diameter at which $90 \%$ of the sand sample is finer than. According to Eqs. (8)-(11), small values of $T_{s}$ correspond to nearly instantaneous sediment response. This means that coarser sand with larger fall velocity corresponds to quicker sediment response. $f_{T_{s}}$ is a factor between 0.01-1.0. In our simulations, we set $f_{T_{S}}=0.1$, which is chosen based on our sensitivity analysis.

The equilibrium sediment concentration $C_{\mathrm{eq}}$ is calculated by van Rijn's formula.

$$
C_{\mathrm{eq}}=\frac{q_{s}+q_{b}}{|u| h}
$$

where $q_{s}$ and $q_{b}$ are sediment volume fluxes for bed load and suspended load, respectively; both are all functions of the sediment grain size, relative density of the sediment and the local water depth (van Rijn, 1993). $|u|$ is the magnitude of the depth-averaged flow velocity. van Rijn (1993) suggested the following expressions for the sediment volume fluxes for bed load and suspended load:

$$
\begin{aligned}
q_{s} & =0.012|u| \frac{\left(|u|-u_{\mathrm{cr}}\right)^{2.4} d_{50} D_{*}^{-0.6}}{\left((s-1) g d_{50}\right)^{1.2}} \\
q_{b} & =0.005|u|\left(\frac{|u|-u_{\mathrm{cr}}}{(s-1) g d_{50}}\right)^{2.4}\left(\frac{d_{50}}{h}\right)^{1.2}
\end{aligned}
$$

where $D_{*}=\left[(s-1) g / v^{2}\right]^{1 / 3} d_{50}$ is the dimensionless particle diameter which reflects the influence of gravity, density and viscosity. $u_{\mathrm{cr}}$ is critical depth-averaged flow velocity. According to van Rijn (1993),

$$
u_{\mathrm{cr}}=0.19\left(d_{50}\right)^{0.1} \log \left(12 h / 3 d_{90}\right)
$$


when $0.0001 \leq d_{50} \leq 0.0005$ and

$$
u_{\mathrm{cr}}=8.50\left(d_{50}\right)^{0.6} \log \left(12 h / 3 d_{90}\right)
$$

when $0.0005 \leq d_{50} \leq 0.002$. In the above two equations, the unit of $d_{50}$ is meter.

\section{References}

Ackers, P. and W. R. White, Sediment transport: New approach and analysis, J. Hydraul. Div., 99, 2041-2060, 1973.

Ahrens, J. P., A fall-velocity equation, J. Waterway Port Coast. Ocean Eng., 126, 99-102, 2000.

Apotsos, A., G. Gelfenbaum, and B. Jaffe, Process-based modeling of tsunami inundation and sediment transport, J. Geophys. Res., 116, 20, 2011.

Aydan, O., Seismic and tsunami hazard potentials in Indonesia with a special emphasis on Sumatra Island, Journal of The School of Marine Science and Technology, Tokai University, 6, 19-38, 2008.

Bagnold, R. A., An approach to the sediment transport problem from general physics, Geological Survey Professional Papers, Washington, USA, 1966.

Borrero, J. C., Field survey of northern Sumatra and Banda Aceh, Indonesia after the Tsunami and earthquake of 26 December 2004, Seismol. Res. Lett., 76, 312-320, 2005.

Borrero, J. C., K. Sieh, M. Chlieh, and C. E. Synolakis, Tsunami inundation modeling for western Sumatra, Proc. Natl. Acad. Sci. USA, 103, 19673-19677, 2006.

Bourgeois, J., Geologic effects and records of tsunamis, in The Sea: Tsunamis, edited by E. N. Bernard and A. R. Robinson, Harvard University Press, London, England, 2009.

Brooks, O., Tsunami Alert: Beating Asia’s Next Big One, 215 pp., Marshall Cavendish Editions, Singapore, 2010.

Carrier, G. F. and H. P. Greenspan, Water waves of finite amplitude on a sloping beach, J. Fluid Mech., 4, 97-109, 1958.

Chien, N. and Z. Wan, Mechanics of Sediment Transport, 913 pp., American Society of Civil Engineers, 1999.

Chlieh, M., J. P. Avouac, K. Sieh, D. H. Natawidjaja, and J. Galetzka, Heterogeneous coupling of the Sumatran megathrust constrained by geodetic and paleogeodetic measurements, J. Geophys. Res. B: Solid Earth, 113, 2008.

Dawson, A. G., S. Shi, S. Dawson, T. Takahashi, and N. Shuto, Coastal sedimentation associated with the June 2nd and 3rd, 1994 Tsunami in Rajegwesi, Java, Quat. Sci. Rev., 15, 901-912, 1996.

Deltares, XBeach Testbed Report, Delft, The Netherlands, 2010.

Folk, R. L. and W. C. Ward, Brazos River Bar: A study in the significance of grain size parameters, J. Sediment. Petrol., 27, 3-26, 1957.

Galappatti, G. and C. B. Vreugdenhil, A depth-integrated model for suspended sediment transport, J. Hydraul. Res., 23, 359-377, 1985.

Gelfenbaum, G. and B. Jaffe, Erosion and sedimentation from the 17 July, 1998 Papua New Guinea tsunami, Pure Appl. Geophys., 160, 19691999, 2003.

Gelfenbaum, G., D. Vatvani, B. Jaffe, and F. Dekker, Tsunami inundation and sediment transport in vicinity of coastal mangrove forest, Coast. Sediment., 1-12, 2007.

Goseberg, N. and T. Schlurmann, Relevant factors on the extent of inundation based on tsunami scenarios for the city of Padang, West Sumatra, in Proceedings of the International Conference on Tsunami Warning $(I C T W)$, Bali, Indonesia, 2008.

Goto, K. and F. Imamura, Numerical models for sediment transport by tsunamis, Quatern. Res., 46, 463-475, 2007.

Goto, K., S. A. Chavanich, F. Imamura, P. Kunthasap, T. Matsui, K. Minoura, D. Sugawara, and H. Yanagisawa, Distribution, origin and transport process of boulders deposited by the 2004 Indian Ocean tsunami at Pakarang Cape, Thailand, Sediment. Geol., 202, 821-837, 2007.

Huang, Z. H., T. R. Wu, S. K. Tan, K. Megawati, F. Shaw, X. Z. Liu, and T. C. Pan, Tsunami hazard from the subduction Megathrust of the South China Sea: Part II. Hydrodynamic modeling and possible impact on Singapore, J. Asian Earth Sci., 36, 93-97, 2009.

Huang, Z. H., Q. Qiu, K. Sieh, K. Megawati, D. H. Natawidjaja, and $\mathrm{X}$. Wang, Numerical simulations of tsunami inundation for the city of Painan, Indonesia-Effects of coastal vegetations and man-made structures, in Tsunami Simulation for Impact Assessment, edited by $\mathrm{H}$. L. Koh, P. L.-F. Liu, and S. Y. Teh, 249 pp., Penerbit Universiti Sains Malaysia, Malaysia, 2011.
Imamura, F., I. Yoshida, and A. Moore, Numerical study of the 1771 Meiwa tsunami at Ishigaki island, Okinawa and the movement of the tsunami stones, in Proceedings of Coastal Engineering, Japan Society of Civil Engineers, 48, 346-350, 2001.

Jaffe, B. E. and G. Gelfenbuam, A simple model for calculating tsunami flow speed from tsunami deposits, Sediment. Geol., 200, 347-361, 2007.

Jimenez, J. A., A. H. Sallenger, and L. Fauver, Sediment transport and barrier island changes during massive overwash events, in Proceedings of the 30th International Conference on Coastal Engineering, ASCE, 2870-2879, San Diego, USA, 2006

Kato, F., S. Sato, and Y. E. H. Harry, Large-scale experiment on dynamic response of sand bed around a cylinder due to tsunami, in Proceedings of the 27th International Conference on Coastal Engineering, ASCE, 1848-1859, Sydney, Australia, 2000.

Kato, F., S. Tonkin, H. Yeh, S. Sato, and K.-I. Torii, The grain-size effects on scour around a cylinder due to tsunami run-up, in Proceedings of the International Tsunami Symposium 2001, 905-917, Seattle, Washington, USA, 2001.

Kobayashi, N. and A. R. Lawrence, Cross-shore sediment transport under breaking solitary waves, J. Geophys. Res. C: Oceans, 109, 2004.

Komar, P. D., Beach Processes and Sedimentation, 429 pp., Prentice-Hall, Inc., Englewood Cliffs, New Jersey, 1976.

Konca, A. O., J. P. Avouac, A. Sladen, A. J. Meltzner, K. Sieh, P. Fang, Z. Li, J. Galetzka, J. Genrich, M. Chlieh, D. H. Natawidjaja, Y. Bock, E. J. Fielding, C. Ji, and D. V. Helmberger, Partial rupture of a locked patch of the Sumatra megathrust during the 2007 earthquake sequence, Nature, 456, 631-635, 2008.

Lindemer, C. A., N. G. Plant, J. A. Puleo, D. M. Thompson, and T. V. Wamsley, Numerical simulation of a low-lying barrier island's morphological response to Hurricane Katrina, Coast. Eng., 57, 985-995, 2010.

Liu, P. L. F., C. Yong-Sik, M. J. Briggs, U. Kanoglu, and C. E. Synolakis, Runup of solitary waves on a circular island, J. Fluid Mech., 302, 259285, 1995.

Lukkunaprasit, P. and A. Ruangrassamee, Building damage in Thailand in the 2004 Indian Ocean tsunami and clues for tsunami-resistant design, The IES Journal Part A: Civil \& Structural Engineering, 1, 17-30, 2008.

Maheshwari, B. K., M. L. S. M. EERI, and J. P. Narayan, Geotechnical and Structural Damage in Tamil Nadu, India, from the December 2004 Indian Ocean Tsunami, Earthq. Spectr., 22, 475-493, 2006.

Martin, M. E., R. Weiss, J. Bourgeois, T. K. Pinegina, H. Houston, and V. V. Titov, Combining constraints from tsunami modeling and sedimentology to untangle the 1969 Ozernoi and 1971 Kamchatskii tsunamis, Geophys. Res. Lett., 35, L01610, 2008.

Matsutomi, H., T. Sakakiyama, S. Nugroho, and M. Matsuyama, Aspects of inundated flow due to the 2004 Indian Ocean Tsunami, Coast. Eng. J., 48, 167-195, 2006.

McCall, R. T., J. S. M. Van Thiel de Vries, N. G. Plant, A. R. Van Dongeren, J. A. Roelvink, D. M. Thompson, and A. J. H. M. Reniers, Twodimensional time dependent hurricane overwash and erosion modeling at Santa Rosa Island, Coast. Eng., 57, 668-683, 2010.

McCloskey, J., S. S. Nalbant, and S. Steacy, Indonesian earthquake: earthquake risk from co-seismic stress, Nature, 434, 291, 2005.

McCloskey, J., A. Antonioli, A. Piatanesi, K. Sieh, S. Steacy, S. Nalbant, M. Cocco, C. Giunchi, J. Huang, and P. Dunlop, Tsunami threat in the Indian Ocean from a future megathrust earthquake west of Sumatra, Earth Planet. Sci. Lett., 265, 61-81, 2008.

Megawati, K., F. Shaw, K. Sieh, Z. H. Huang, T. R. Wu, Y. Lin, S. K. Tan, and T. C. Pan, Tsunami hazard from the subduction megathrust of the South China Sea: Part I. Source characterization and the resulting tsunami, J. Asian Earth Sci., 36, 13-20, 2009.

Meilianda, E., C. M. Dohmen-Janssen, B. H. P. Maathuis, S. J. M. H. Hulscher, and J. P. M. Mulder, Short-term morphological responses and developments of Banda Aceh coast, Sumatra Island, Indonesia after the tsunami on 26 December 2004, Mar. Geol., 275, 96-109, 2010.

Moore, A. L., B. G. McAdoo, and A. Ruffman, Landward fining from multiple sources in a sand sheet deposited by the 1929 Grand Banks tsunami, Newfoundland, Sediment. Geol., 200, 336-346, 2007.

Morton, R. A., J. R. Goff, and S. L. Nichol, Hydrodynamic implications of textural trends in sand deposits of the 2004 tsunami in Sri Lanka, Sediment. Geol., 207, 56-64, 2008.

Muhari, A., F. Imamura, D. H. Natawidjaja, S. Diposaptono, H. Latief, J. Post, and F. A. Ismail, Tsunami mitigation efforts with pTA in west Sumatra province, Indonesia, J. Earthq. Tsunami, 4, 341-368, 2010.

Nakamura, T., Y. Kuramitsu, and N. Mizutani, Tsunami scour around a square structure, Coast. Eng. J., 50, 209-246, 2008.

Nalbant, S. S., S. Steacy, K. Sieh, D. Natawidjaja, and J. McCloskey, 
Seismology: Earthquake risk on the Sunda trench, Nature, 435, 756$757,2005$.

Narayana, A. C., R. Tatavarti, N. Shinu, and A. Subeer, Tsunami of December 26, 2004 on the southwest coast of India: Post-tsunami geomorphic and sediment characteristics, Mar. Geol., 242, 155-168, 2007.

Natawidjaja, D. H. and W. Triyoso, The Sumatran fault zone-from source to hazard, J. Earthq. Tsunami, 1, 21-47, 2007.

Natawidjaja, D. H., K. Sieh, M. Chlieh, J. Galetzka, B. W. Suwargadi, H. Cheng, R. L. Edwards, J.-P. Avouac, and S. N. Ward, Source parameters of the great Sumatran megathrust earthquakes of 1797 and 1833 inferred from coral microatolls, J. Geophys. Res., 111, B06403, 2006.

Natawidjaja, D., K. Sieh, W. Kongko, A. Muhari, G. S. Prasetya, and I. Meilano, Scenario for future megathrust tsunami event in the Sumatran subduction zone, in Proceedings of the Asian Oceania Geo-sciences Society (AOGS) Meeting, Singapore, 2009.

Nelson, A. R., H. M. Kelsey, and R. C. Witter, Great earthquakes of variable magnitude at the Cascadia subduction zone, Quatern. Res., 65 , 354-365, 2006.

Okada, Y., Surface deformation due to shear and tensile faults in a halfspace, Bull. Seismol. Soc. Am., 75, 1135-1154, 1985.

Ozkan-Haller, H. T. and J. T. Kirby, A Fourier-Chebyshev collocation method for the shallow water equations including shoreline runup, Appl. Ocean Res., 19, 21-34, 1997.

Pari, Y., M. V. Ramana Murthy, S. Jaya kumar, B. R. Subramanian, and S. Ramachandran, Morphological changes at Vellar estuary, India-Impact of the December 2004 tsunami, J. Environ. Manag., 89, 45-57, 2008.

Paris, R., F. Lavigne, P. Wassmer, and J. Sartohadi, Coastal sedimentation associated with the December 26, 2004 tsunami in Lhok Nga, west Banda Aceh (Sumatra, Indonesia), Mar. Geol., 238, 93-106, 2007.

Paris, R., P. Wassmer, J. Sartohadi, F. Lavigne, B. Barthomeuf, E. Desgages, D. Grancher, P. Baumert, F. Vautier, D. Brunstein, and C. Gomez, Tsunamis as geomorphic crises: Lessons from the December 26, 2004 tsunami in Lhok Nga, West Banda Aceh (Sumatra, Indonesia), Geomorphology, 104, 59-72, 2009.

Paris, R., J. Fournier, E. Poizot, S. Etienne, J. Morin, F. Lavigne, and P. Wassmer, Boulder and fine sediment transport and deposition by the 2004 tsunami in Lhok Nga (western Banda Aceh, Sumatra, Indonesia): A coupled offshore-onshore model, Mar. Geol., 268, 43-54, 2010.

Qiu, Q., Z. H. Huang, K. Megawati, K. Sieh, and D. H. Natawidjaja, A scenario study of tsunami-induced inundation for Pariaman, West Sumatra, Indonesia, in Proceedings of 5th Annual International Workshop \& Expro on Sumatra Tsunami Disaster \& Recovery 2010, Banda Aceh, Indonesia, 2010.

Richardson, J. F. and W. N. Zaki, Sedimentation and fluidization, Trans. Inst. Chem. Eng., 32, 35-50, 1954.

Roelvink, D., A. Reniers, A. van Dongeren, J. van Thiel de Vries, R. McCall, and J. Lescinski, Modelling storm impacts on beaches, dunes and barrier islands, Coast. Eng., 56, 1133-1152, 2009.

Shi, S., A. G. Dawson, and D. E. Smith, Coastal sedimentation associated with the December 12th, 1992 tsunami in Flores, Indonesia, Pure Appl. Geophys., 144, 525-536, 1995.

Shuto, N., Tsunami intensity and Disasters, Adv. Nat. Technol. Haz. Res., 1, 197-216, 1993.
Sieh, K., The Sunda magathrust-past, present and future, J. Earthq. Tsunami, 1, 1-19, 2007.

Sieh, K., D. H. Natawidjaja, A. J. Meltzner, C. C. Shen, H. Cheng, K. S. Li, B. W. Suwargadi, J. Galetzka, B. Philibosian, and R. L. Edwards, Earthquake supercycles inferred from sea-level changes recorded in the corals of west Sumatra, Science, 322, 1674-1678, 2008.

Spiske, M., R. Weiss, H. Bahlburg, J. Roskosch, and H. Amijaya, The TsuSedMod inversion model applied to the deposits of the 2004 Sumatra and 2006 Java tsunami and implications for estimating flow parameters of palaeo-tsunami, Sediment. Geol., 224, 29-37, 2010.

Srinivasalu, S., N. Thangadurai, A. D. Switzer, V. Ram Mohan, and T. Ayyamperumal, Erosion and sedimentation in Kalpakkam (N Tamil Nadu, India) from the 26th December 2004 tsunami, Mar. Geol., 240, 65-75, 2007.

Takahashi, T., N. Shuto, F. Imamura, and D. Asai, Modeling sediment transport due to tsunamis with exchange rate between bed load layer and suspended load layer,in Proceedings of the 27th International Conference on Coastal Engineering, ASCE, 1508-1519, Sydney, Australia, 2000.

Taubenbock, H., N. Goseberg, N. Setiadi, G. Lämmel, F. Moder, M. Oczipka, H. Klüpfel, R. Wahl, T. Schlurmann, G. Strunz, J. Birkmann, K. Nagel, F. Siegert, F. Lehmann, S. Dech, A. Gress, and R. Klein, "Last-Mile" preparation for a potential disaster-Interdisciplinary approach towards tsunami early warning and an evacuation information system for the coastal city of Padang, Indonesia, Nat. Haz. Earth Syst. Sci., 9, 1509-1528, 2009.

Tobita, M., Crustal deformation of 2007 Southern Sumatra earthquake observed by SAR interferometry, in Proceedings of DPRI(Disaster Prevention Research Institute) Kyoto Workshop, Kyoto, Japan, 2007.

Tonkin, S., H. Yeh, F. Kato, and S. Sato, Tsunami scour around a cylinder, J. Fluid Mech., 165-192, 2003.

van Rijn, L. C., Principles of Sediment Transport in Rivers, Estuaries and Coastal Seas, 715 pp., Aqua Publications, The Netherlands, 1993.

van Rijn, L. C., Unified view of sediment transport by currents and waves. II: Suspended transport, J. Hydraul. Eng., 133, 668-689, 2007.

Wang, X. and P. L. F. Liu, A numerical investigation of BoumerdesZemmouri (Algeria) earthquake and Tsunami, Comput. Model. Eng. Sci., 10, 171-183, 2005.

Wijettunge, J. J., X. Wang, and P. L. F. Liu, India Ocean Tsunami on 26 December 2004: Numerical modeling of inundation in three cities on the south coast of Sri Lanka, J. Earthq. Tsunami, 2(2), 133-155, 2008.

Young, Y. L., H. Xiao, and T. Maddux, Hydro- and morpho-dynamic modeling of breaking solitary waves over a fine sand beach. Part I: Experimental study, Mar. Geol., 269, 107-118, 2010.

Zachariasen, J., K. Sieh, F. W. Taylor, R. L. Edwards, and W. S. Hantoro, Submergence and uplift associated with the giant 1833 Sumatran subduction earthquake: Evidence from coral microatolls, J. Geophys. Res., 104, 895-919, 1999.

L. L. Li, Z. H. Huang (e-mail: zhhuang@ntu.edu.sg), Q. Qiu, D. H. Natawidjaja, and K. Sieh 